\title{
Extending the Row of Lanthanide Tetrafluorides: A Combined Matrix-Isolation and Quantum-Chemical Study
}

\author{
Thomas Vent-Schmidt, ${ }^{[a]}$ Zongtang Fang, ${ }^{[b]}$ Zachary Lee, ${ }^{[b]}$ David Dixon, ${ }^{[b]}$ and \\ Sebastian Riedel*[c]
}

\begin{abstract}
Only the neutral tetrafluorides of $\mathrm{Ce}, \mathrm{Pr}$, and $\mathrm{Tb}$ as well as the $\left[\mathrm{LnF}_{7}\right]^{3-}$ anions of $\mathrm{Dy}$ and $\mathrm{Nd}$, with the metal in the + IV oxidation state, have been previously reported. We report our attempts to extend the row of neutral lanthanide tetrafluorides through the reaction of laser-ablated metal atoms with fluorine and their stabilization and characterization by matrix-isolation IR spectroscopy. In addition to the above three tetrafluorides, we found two new tetrafluorides, ${ }^{3} \mathrm{NdF}_{4}$ and ${ }^{7} \mathrm{DyF}_{4}$, both of which are in the + IV oxidation
\end{abstract}

state, which extends this lanthanide oxidation state to two new metals. Our experimental results are supported by quantum-chemical calculations and the role of the lanthanide oxidation state is discussed for both the $\mathrm{LnF}_{4}$ and $\left[\mathrm{LnF}_{4}\right]^{-}$species. Most of the $\mathrm{LnF}_{4}$ species are predicted to be in the + IV oxidation state and all of the $\left[\mathrm{LnF}_{4}\right]^{-}$anions are predicted to be in the + III oxidation state. The $\mathrm{LnF}_{4}$ species are predicted to be strong oxidizing agents and the $\mathrm{LnF}_{3}$ species are predicted to be moderate to strong Lewis acids.

\section{Introduction}

The properties of lanthanides and actinides have sparked substantial interest, particularly with regard to understanding the role of valence $d$ and $f$ orbitals in the bonding of ligands to the metal center. Reactions involving lanthanide atoms exhibit trends across the series because of the presence of electrons in the $4 \mathrm{f}$ orbitals, even though $4 \mathrm{f}$ electrons are usually considered to be inert in terms of the bonding of molecules containing lanthanides. The chemistry of the lanthanides is mostly dominated by compounds in the oxidation state + III owing to the relative inertness of the $4 \mathrm{f}$ electrons caused by the contracted radial distribution and the relatively low energy (stabili-

\section{[a] T. Vent-Schmid}

Albert-Ludwigs-Universität Freiburg

Institut für Anorganische und Analytische Chemie

Albertstrasse 21, 79104 Freiburg (Germany)

[b] Dr. Z. Fang, Z. Lee, Prof. Dr. D. Dixon

Department of Chemistry, The University of Alabama

Tuscaloosa, Alabama 35487-0336 (USA)

E-mail:dadixon@bama.ua.edu

[c] Prof. Dr. S. Riedel

Freie Universität Berlin, Institut für Chemie und Biochemie

Fabeckstrasse 34-36, 14195 Berlin (Germany)

E-mail: sriedel@fu-berlin.de

$\square$ Supporting information for this article is available on the WWW under http://dx.doi.org/10.1002/chem.201504182. It contains spin density images at the 0.02 contour level for $\mathrm{LnF}_{4}$; spin density images at the 0.02 contour level for $\left[\mathrm{LnF}_{4}\right]^{-}$; calculated symmetric (sym) and asymmetric (asym) $\mathrm{Ln}-\mathrm{F}$ vibrational frequencies $\left(\mathrm{cm}^{-1}\right)$ and intensities $\left(\mathrm{km} \mathrm{mol}^{-1}\right)$ at the MP2/Stuttgart/aug-cc-pVDZ level and the experimental matrix infrared vibrational frequencies $\left(\mathrm{cm}^{-1}\right)$ for $\mathrm{LnF}_{3}$ and $\mathrm{LnF}_{2} ; B 3 L Y P / S t$ tutgart/DZVP2 population analysis for $\mathrm{LnF}_{4} ; \mathrm{B} 3 \mathrm{LYP} / \mathrm{Stuttgart/DZVP2}$ population analysis for $\left[\mathrm{LnF}_{4}\right]^{-}$; Cartesian coordinates for optimized cerium species, zero point energies (ZPE, a.u.), enthalpy correction $\left(\Delta \mathrm{H}_{298}\right.$, a.u.) at $298 \mathrm{~K}$, and electronic energies at $0 K\left(\mathrm{E}_{M, 0 K}\right.$, a.u. $)$ at the MP2/Stuttgart/aug-cc-pVDZ level. ty) of these orbitals. The lanthanide trifluorides have been the subject of numerous experimental and theoretical investigations owing to their special electronic structure and the question as to whether their structures have $C_{3 v}$ or $D_{3 h}$ symmetry. ${ }^{[1-12]}$ There is substantial interest in the formation of novel oxidation states of the lanthanides, notably through the work of Evans and co-workers who have found complexes of $L n$ in the + II formal oxidation state in contrast to the usual + III oxidation state. ${ }^{[13,14,15]}$ The available work on the + II oxidation state has recently been summarized by Meyer; ${ }^{[16]}$ we note that only a few difluorides are known. ${ }^{[2,17]}$ The + IV oxidation state $^{[18]}$ is known for the tetrafluorides of Ce, Pr, and $\mathrm{Tb}^{[19,20,21,22]}$ and some oxides ${ }^{[23]}$ and fluorine oxides. In the case of $\mathrm{Ln}$ reacting with $\mathrm{OF}_{2}, \mathrm{LnOF}_{2}$ and $\mathrm{LnOF}$ were the two products observed in the argon matrix. ${ }^{[24]}$ The LnOF species always have the $\mathrm{Ln}$ in the + III oxidation state and the $\mathrm{LnOF}_{2}$ usually have the $\mathrm{Ln}$ in the + III oxidation state with the $\mathrm{O}$ in the formal -I oxidation state and a spin on the O. Only a + IV oxidation state for Ce and a mixed + III/IV oxidation state for $\mathrm{Pr}$ and $\mathrm{Tb}$ show deviations from the + III oxidation state. Solids of the formula $M_{3} \mathrm{LnF}_{7}$ ( $\mathrm{Ln}=$ lanthanide; $\mathrm{M}=$ alkali metal) where the $\left[\mathrm{LnF}_{7}\right]^{3-}$ anion contains a lanthanide in the formal oxidation state + IV are known for neodymium and dysprosium. ${ }^{[25,26]}$ However, the neutral tetrafluorides $\mathrm{NdF}_{4}$ and $\mathrm{DyF}_{4}$ are so far unknown. The reaction of laser-ablated lanthanide atoms with fluorine has so far only been reported for the $\mathrm{Pr} / \mathrm{F}_{2}$ system where the stability of a possible praseodymium pentafluoride was discussed. ${ }^{[27]}$ In this study, we continue the investigation of the $L n / F_{2}$ systems to extend the known neutral lanthanide tetrafluorides. This extends matrix-isolation infrared spectroscopic studies of the lanthanides with $\mathrm{CH}_{3} \mathrm{~F}_{1}{ }^{[12]} \mathrm{CH}_{2} \mathrm{~F}_{2}{ }^{\left[{ }^{[28]}\right.} \mathrm{CHF}_{3,}{ }^{[29]}$ $\mathrm{CH}_{3} \mathrm{OH}_{1}{ }^{[30]}$ and $\mathrm{OF}_{2} \cdot{ }^{[24]}$ In most of these cases, the $\mathrm{Ln}$ is in the + III oxidation state, which means that there is usually an un- 
paired electron on the $\mathrm{C}$ or $\mathrm{O}$. We have used a combination of matrix-isolation infrared spectroscopy and computational chemistry to study the $\mathrm{LnF}_{4}$ compounds.

\section{Experimental and Computational Details}

\section{Matrix-isolation experiments}

Fluorine (99.8\%, Solvay) was premixed with neon (99.999\%, Air Liquide) or argon (both $99.999 \%$, Sauerstoffwerk Friedrichshafen) in a stainless steel cylinder. The mixing vessel was connected to a self-made matrix chamber by a stainless steel capillary. The reactants were condensed onto a Csl window cooled to $4 \mathrm{~K}$ (neon) or $10 \mathrm{~K}$ (argon and fluorine) by using a closed-cycle helium cryostat (Sumitomo Heavy Industries, RDK-205D) inside the vacuum chamber. In experiments using neat fluorine, the fluorine cylinder was cooled to $77 \mathrm{~K}$ to freeze out common impurities such as $\mathrm{CF}_{4}, \mathrm{OF}_{2}, \mathrm{COF}_{2}$, and HF. For the laser-ablation experiments, the $1064 \mathrm{~nm}$ fundamental of a Nd:YAG laser (Continuum, Minilite II, $10 \mathrm{~Hz}$ repetition rate, 35-50 m J pulse ${ }^{-1}$ ) was used, which was focused onto a rotating lanthanide metal target through a hole in the cold window. The metal targets were polished before use to remove the oxide layer and to avoid oxyfluoride contamination. Infrared spectra were recorded on a Bruker Vertex 70 spectrometer purged with dry air at $0.5 \mathrm{~cm}^{-1}$ resolution in the region 4000 $430 \mathrm{~cm}^{-1}$ by using a liquid-nitrogen-cooled mercury cadmium telluride (MCT) detector. The matrix samples were irradiated by a mercury arc street lamp (Osram HQL 250) with the outer globe removed.

\section{Electronic-structure calculations}

The electronic-structure calculations were initially performed at the density functional theory (DFT) ${ }^{[31]}$ level with the hybrid B3LYP ${ }^{[32,33]}$ exchange-correlation functional with the DFT-optimized DZVP2 basis set ${ }^{[34]}$ on $\mathrm{F}$ and the small core relativistic effective core potential (ECP) from the Stuttgart group (ECP28MWB) with corresponding segmented basis set (ECP28MWB_SEG) on the lanthanide metals. There are 28 electrons subsumed in the ECP, leaving the $4 s, 4 p, 4 d, 5 s, 5 p, 6 s$, and $4 \mathrm{f}$ (and/or $5 \mathrm{~d}$ ) electrons in the valence space for the $\mathrm{Ln}$. The $L n$ basis set is of the form (14s, 13p, 10d, 8f, 6g/10s, 8p, $5 \mathrm{~d}, 4 \mathrm{f}, 2 \mathrm{~g}$ ), and we denote this as the Stuttgart basis set. ${ }^{[35,36]}$ This combination of basis sets and exchange-correlation functional has been found to work well in our analysis of similar reactions with lanthanides. ${ }^{[12,24,28,29,30]}$ These calculations were performed on each $\mathrm{LnF}_{4}$ and $\left[\mathrm{LnF}_{4}\right]^{-}$complex with different spin states. In many cases, the DFT results were not satisfactory as discussed below so the calculations were redone at the second-order Møller-Plesset (MP2) level ${ }^{[37,38]}$ with the above basis set for the Ln and the aug-cc-pVDZ basis set ${ }^{[39]}$ on F. The electronic structure was probed by using the $\mathrm{NBO}^{[40,41,42,43,44]}$ program. The calculations were done with the Gaussian 09 program system. ${ }^{[45]}$

\section{Results and Discussion}

\section{Matrix experiments}

The reaction of the laser-ablated lanthanide atoms with fluorine in excess noble gas yielded the lanthanide trifluorides for all metals and the tetrafluorides for $\mathrm{Ce}, \mathrm{Pr}, \mathrm{Nd}, \mathrm{Tb}$, and $\mathrm{Dy}$ as well as possibly the difluorides of $\mathrm{Pr}, \mathrm{Nd}$, and $\mathrm{Sm}$. The trifluoride of $\mathrm{Sm}$ shows only one fundamental, which is indicative of a $D_{3 h}$ symmetric structure whereas $\mathrm{CeF}_{3}, \mathrm{PrF}_{3}, \mathrm{NdF}_{3}, \mathrm{TbF}_{3}, \mathrm{DyF}_{3}$, and $\mathrm{HoF}_{3}$ show two frequencies, so they have $C_{3 v}$ symmetry within the matrix. Figure 1 shows a comparison of spectra obtained for the investigated $L n / F_{2}$ systems in argon whereas Figure 2 compares the neon-based spectra.

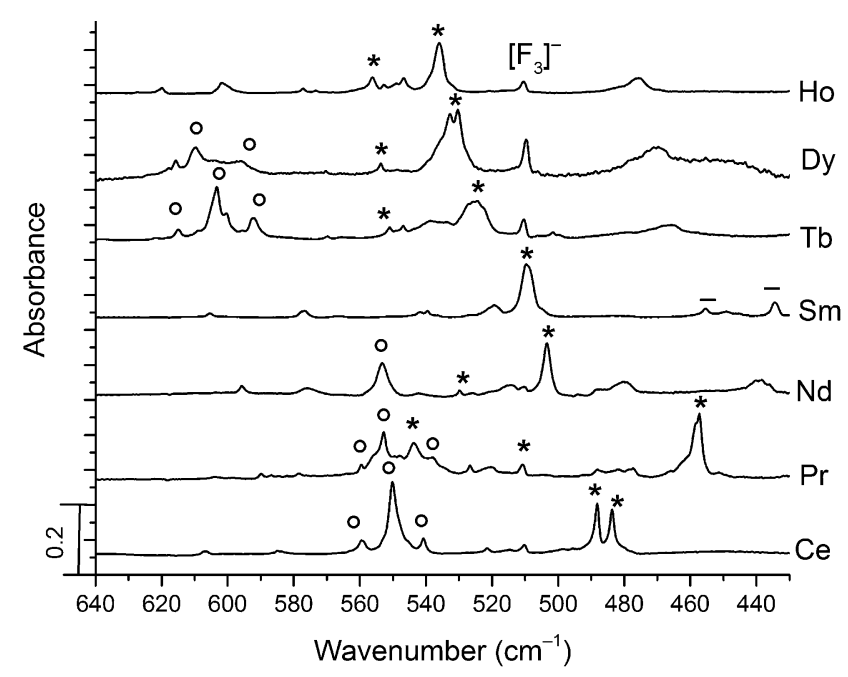

Figure 1. Reaction products of laser-ablated lanthanide atoms with $F_{2}$ in excess argon. Asterisks mark $\mathrm{LnF}_{3}$ compounds, bars correspond to $\mathrm{SmF}_{2}$, whereas circles mark tetrafluorides. For better comparison, some of the spectra have been scaled.

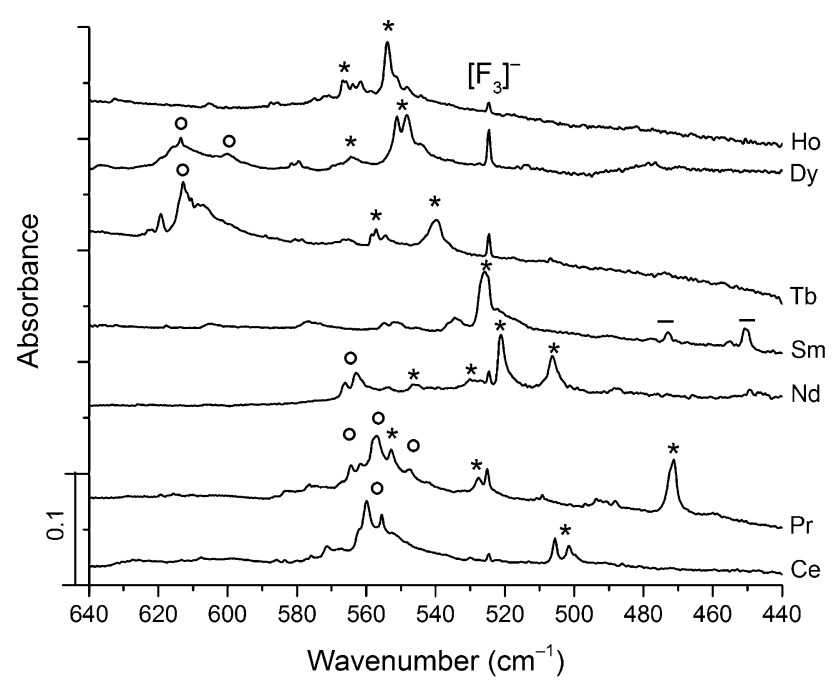

Figure 2. Reaction products of laser-ablated lanthanide atoms with $\mathrm{F}_{2}$ in excess neon. Asterisks mark $\mathrm{LnF}_{3}$ compounds, bars correspond to $\mathrm{SmF}_{2}$, whereas circles mark tetrafluorides. For better comparison, some of the spectra have been scaled. 


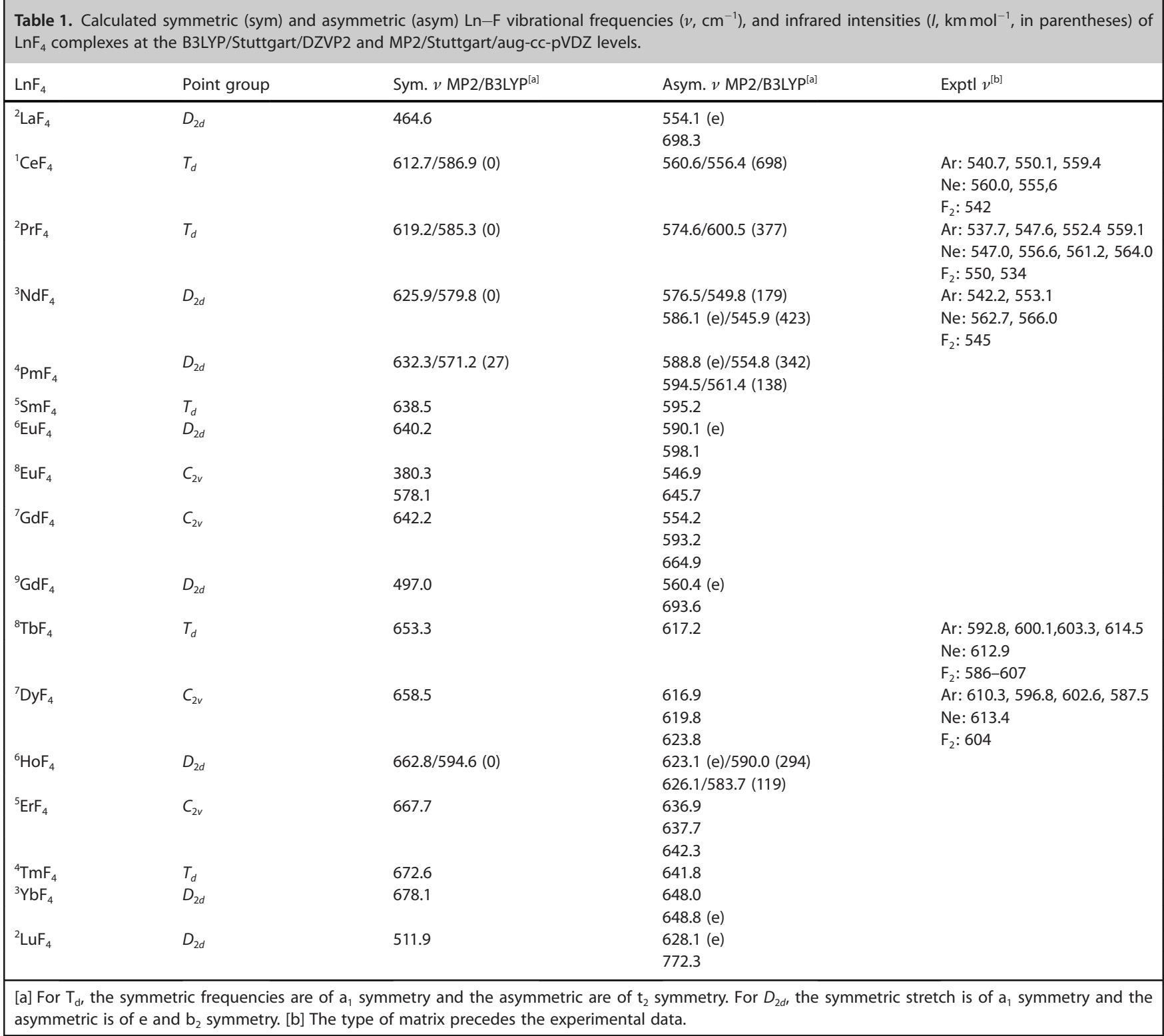

In all experiments, the previously reported trifluoride anion, $\left[\mathrm{F}_{3}\right]^{-}$, could be found at $510.6 \mathrm{in}$ argon and at $524.7 \mathrm{~cm}^{-1}$ in neon. ${ }^{[46]}$ In the neon experiments, the recently found $\left[\mathrm{F}_{5}\right]^{-}$ anion was also observed at $850.7 \mathrm{~cm}^{-1} \cdot{ }^{[47,48]}$ As recently reported by Mikulas et al., ${ }^{[24]}$ we also checked our spectra for lanthanide oxyfluorides, which might arise from the laser-ablated metal oxides surface with fluorine. However, no bands for the expected LnOF or $\mathrm{LnOF}_{2}$ molecules were found. ${ }^{[24]}$ The following discussion is based on the argon spectra for convenience, although a similar discussion is valid for the neon experiments. All of the values can be found in Table 1 .

We first discuss the $\mathrm{Ce} / \mathrm{F}_{2}$ system as the $\mathrm{Ce}$ can readily attain the + IV oxidation state. Figure 3 shows the reaction products of laser-ablated cerium atoms with fluorine in argon. On sample deposition, a characteristic doublet splitting for the $v_{3}(E)$ mode of $\mathrm{CeF}_{3}$ at 488.3 and $483.6 \mathrm{~cm}^{-1}$ along with a weaker $v_{1}\left(A_{1}\right)$ mode at $521.8 \mathrm{~cm}^{-1}$ were observed and these agree well with previously reported bands. ${ }^{[11]}$ The strong $v_{3}\left(T_{2}\right)$ mode of $\mathrm{CeF}_{4}$ is found at $550.1 \mathrm{~cm}^{-1}$ with matrix sites at 540.8 and $559.5 \mathrm{~cm}^{-1}$ in accordance with prior experimental ${ }^{[49]}$ and computational $^{[50]}$ results. On annealing, the main band at $550.1 \mathrm{~cm}^{-1}$ as well as the trifluoride bands decrease and two other bands at 545.4 and $538.4 \mathrm{~cm}^{-1}$, assigned to $\mathrm{CeF}_{4}$ in a different matrix environment (Figure $3 \mathrm{~b}, \mathrm{c}, \mathrm{f}$, and $\mathrm{g}$ ), increase. Based on the spectra, it is difficult to determine whether new $\mathrm{CeF}_{4}$ is formed on annealing, which is supported by the decrease of $\mathrm{CeF}_{3}$, or if there is just a matrix reorganization. On irradiation with the full spectrum of a mercury arc, the tetrafluoride is formed at the expense of $\mathrm{CeF}_{3}$ (Figure $3 \mathrm{~d}$ and $\mathrm{h}$ ). On further annealing to $35 \mathrm{~K}$, the matrix begins to evaporate. The formation of $\mathrm{CeF}_{4}$ on photolysis and the decrease of $\mathrm{CeF}_{3}$ during the experiment shows that the tetrafluoride is the most stable fluoride under these conditions. 


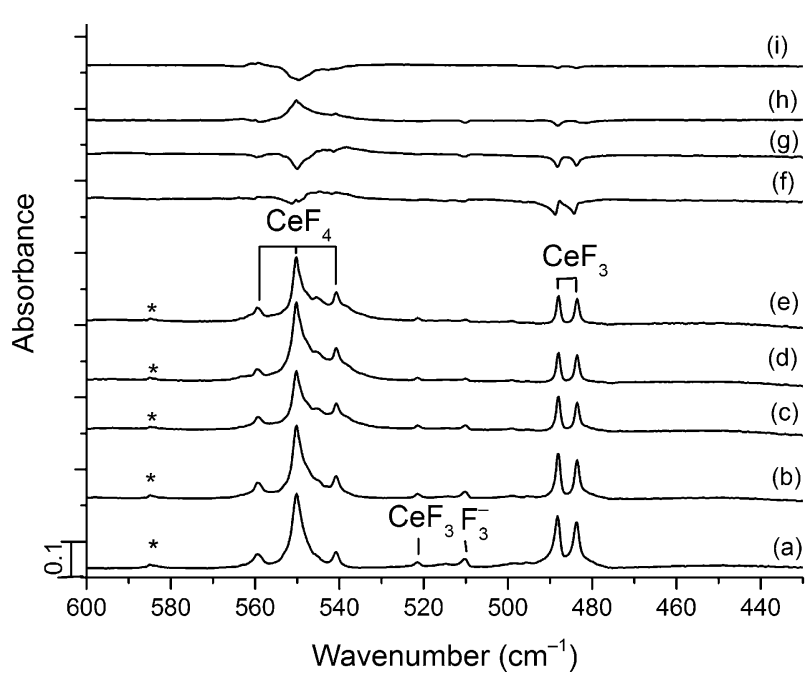

Figure 3. Reaction products of laser-ablated cerium atoms with $2 \% \mathrm{~F}_{2}$ in excess argon. (a) Deposition, (b) annealing to $25 \mathrm{~K}$, (c) annealing to $31 \mathrm{~K}$, (d) UV photolysis for $30 \mathrm{~min}$, (e) annealing to $35 \mathrm{~K}$, (f) difference (b)-(a), (g) difference (c)-(b), (h) difference (d) - (c), (i) difference (e)-(d). Asterisks mark unknown metal independent impurities.

The $\mathrm{Pr} / \mathrm{F}_{2}$ system is the subject of a recently published investigation and will not be discussed in detail herein. ${ }^{[27]}$ However, some points are noteworthy for our discussion. The product spectrum of laser-ablated $\mathrm{Pr}$ atoms with $\mathrm{F}_{2}$ shows $\mathrm{PrF}_{4}$ and $\mathrm{PrF}_{3}$ as the main products and there is evidence for the low-valent fluorides $\operatorname{PrF}\left(\mathrm{Pr}^{\prime}\right)$ and $\mathrm{PrF}_{2}\left(\mathrm{Pr}^{\prime \prime}\right)$. $\mathrm{PrF}_{4}$ is formed on annealing at the expense of $\mathrm{PrF}_{3}$ and the tentatively assigned low-valent fluorides. In contrast to $\mathrm{CeF}_{4}$, praseodymium tetrafluoride decomposes on photolysis and $\mathrm{PrF}_{3}$ is regenerated.

Figure 4 shows the reaction products of laser-ablated $\mathrm{Nd}$ atoms with $\mathrm{F}_{2}$ in argon. On deposition, known bands for $\mathrm{NdF}_{3}$ were found at 503.0 and $529.7 \mathrm{~cm}^{-1}$. ${ }^{11]}$ The new $\mathrm{NdF}_{4}$ molecule

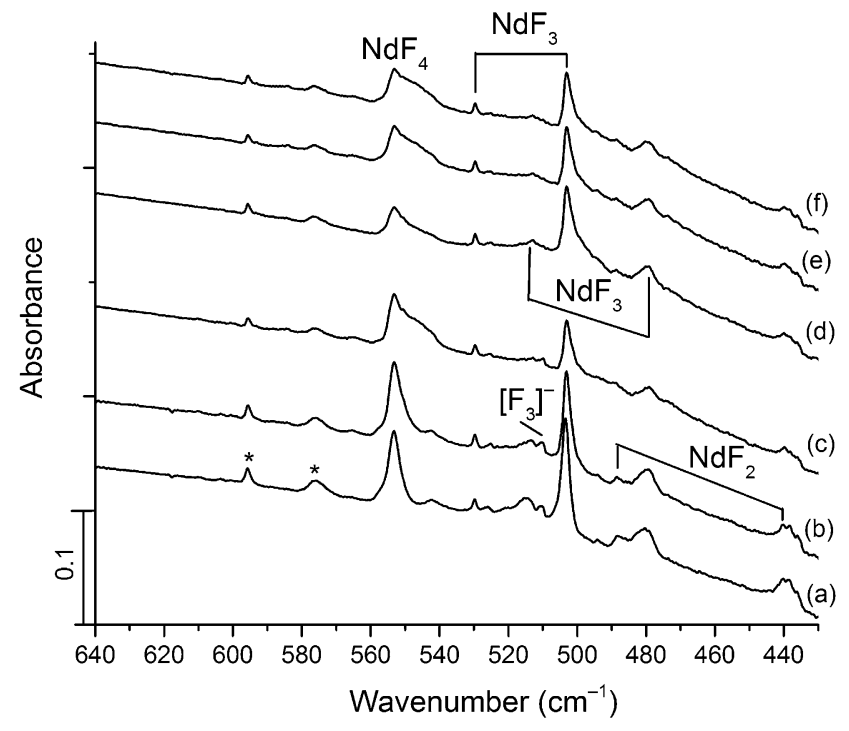

Figure 4. Reaction products of laser-ablated neodymium atoms with $1 \% \mathrm{~F}_{2}$ in excess argon. (a) Deposition, (b) annealing to $25 \mathrm{~K}$, (c) annealing to $29 \mathrm{~K}$ for $2 \mathrm{~min}$, (d) UV photolysis for $30 \mathrm{~min}$, (e) annealing to $28 \mathrm{~K}$ for $2 \mathrm{~min}$, (f) annealing to $35 \mathrm{~K}$. Asterisks mark unknown metal independent impurities. is found at $553.1 \mathrm{~cm}^{-1}$ with a weaker band at $542.2 \mathrm{~cm}^{-1}$. The assignment to the tetrafluoride is made on the basis of three observations. First, on annealing (Figure $4 \mathrm{~b}$ and $\mathrm{c}$ ), these bands grow in at the expense of $\mathrm{NdF}_{3}$, which is characteristic for a higher fluoride. Second, on photolysis (Figure $4 \mathrm{~d}$ ), the compound decomposes and the bands for $\mathrm{NdF}_{3}$ increase. This behavior is the same as that for $\operatorname{PrF}_{4}$, but is in contrast to $\mathrm{CeF}_{4}$, which indicates the lower stability of $\mathrm{PrF}_{4}$ and $\mathrm{NdF}_{4}$. Third, the $\mathrm{Ln}-\mathrm{F}$ stretching frequencies follow the lanthanide contraction. As the $\mathrm{Ln}-\mathrm{F}$ bonds in the tetrafluorides can be considered as even more ionic than the ones in the trifluorides, the same trend is expected for these compounds. Figures 1 and 2 show that there is a blueshift of $2.3 \mathrm{~cm}^{-1}$ from $\mathrm{CeF}_{4}$ to $\mathrm{PrF}_{4}$ and of $1.0 \mathrm{~cm}^{-1}$ from $\mathrm{PrF}_{4}$ to $\mathrm{NdF}_{4}$. These blueshifts are remarkably lower than those observed for the trifluorides.

On annealing, in the $\mathrm{Nd} / \mathrm{F}_{2}$ spectra, a shoulder shifted to lower wavenumbers with respect to the sharp tetrafluoride peak grows in. The band decreases in unison with the band at $533.1 \mathrm{~cm}^{-1}$ on photolysis and is reformed after subsequent annealing. We hypothesize that this is not a new compound, but is either a second stable matrix site of $\mathrm{NdF}_{4}$ or a slightly less stable electronic state, which leads to a small structural change. Additional bands are found at 515.5, 488.3, 479.8, and $439.8 \mathrm{~cm}^{-1}$, of which the 515.5 and the $479.8 \mathrm{~cm}^{-1}$ bands track each other. These latter two bands are known from the work of Hauge et al. and can be assigned to another stable matrix site of $\mathrm{NdF}_{3}{ }^{[10]}$ In neon, two sites are also observed, the $v_{1}\left(A_{1}\right)$ and $v_{3}(E)$ bands are located at 530.1 and $506.7 \mathrm{~cm}^{-1}$ as well as at 546.5 and $521.3 \mathrm{~cm}^{-1}$ for the second site, which is also in line with the literature. ${ }^{[10}$ The bands at 488.3 and $439.8 \mathrm{~cm}^{-1}$ also seem to track each other and could be tentatively assigned to $\mathrm{NdF}_{2}$ by comparison with the known bands of $\mathrm{SmF}_{2}$, which are in the same spectral range and show the same intensity distribution and behavior on annealing and photolysis.

The $\mathrm{Sm} / \mathrm{F}_{2}$ spectrum (Figure 1 and Figure 2) shows no evidence for the formation of a tetrafluoride. The main product band of $\mathrm{SmF}_{3}$ is observed at $508.7 \mathrm{~cm}^{-1}$ and weaker bands for the difluoride are at 455.1 and $434.5 \mathrm{~cm}^{-1}$, both in accordance with literature. ${ }^{[2]} \mathrm{SmF}_{3}$ is formed on photolysis while the main product band decreases on annealing and weak shoulder bands shifted to lower wavenumbers grow in. These bands, as well as similar bands for the modes observed at 519.3, 539.4, and $541.9 \mathrm{~cm}^{-1}$, were previously found in experiments with Knudsen cell evaporated $\mathrm{SmF}_{3}$ and can be tentatively assigned to polymer bands. ${ }^{[2]}$

The chemical behavior on annealing and photolysis of the $\mathrm{Tb} / \mathrm{F}_{2}$ system is the same as for the $\mathrm{Ce} / \mathrm{F}_{2}$ system, which indicates that $\mathrm{TbF}_{4}$ is the most stable compound in the system under cryogenic conditions. Bands for $\mathrm{TbF}_{3}$ are found at 523.6 and $550.9 \mathrm{~cm}^{-1}$ in accordance with the literature ${ }^{[10]}$ and at $603.3 \mathrm{~cm}^{-1}$ for $\mathrm{TbF}_{4}$, with matrix splittings at 592.8, 596.4, 600.1 , and $612.2 \mathrm{~cm}^{-1}$. ${ }^{[22]}$ Additional bands are found at 536.8 and $466.1 \mathrm{~cm}^{-1}$, which could not be assigned. One possibility would be the unknown $\mathrm{TbF}_{2}$ molecule. However, the bands for this compound are expected to be shifted to lower wavenumbers than $\mathrm{TbF}_{3}$ and do not match our calculated values. It is 
also expect that an unstable difluoride would rapidly vanish on annealing, which is not the case. The chemical behavior also does not fit to a possible charged species. As these bands track with the modes of $\mathrm{TbF}_{3}$ and as these bands are not observed in neat fluorine experiments, they might belong to the trifluoride dimer or polymers.

The product spectrum of the $D y / F_{2}$ system shows distinctive bands of $\mathrm{DyF}_{3}$ at $554.0 \mathrm{~cm}^{-1}\left(v_{1}\left(A_{1}\right)\right)$ and a split $v_{3}(E)$ fundamental at 530.6 and $533.0 \mathrm{~cm}^{-1}$ (Figure 5). ${ }^{[51,52]}$ Unknown absorptions were found in the region of a possible tetrafluoride at

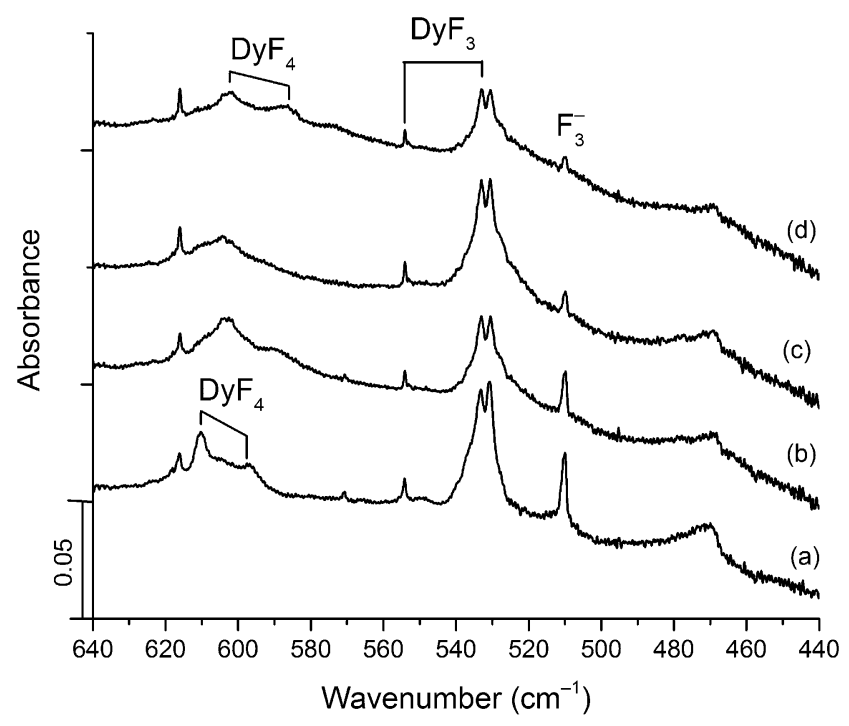

Figure 5. Reaction products of laser-ablated dysprosium atoms with $2 \% F_{2}$ in excess argon measured at $0.2 \mathrm{~cm}^{-1}$ resolution. (a) Deposition, (b) annealing to $30 \mathrm{~K}$, (c) UV photolysis for $30 \mathrm{~min}$, (d) annealing to $35 \mathrm{~K}$.

610.3 and $596.8 \mathrm{~cm}^{-1}$ on deposition. These bands are assigned to the new $\mathrm{DyF}_{4}$ molecule because they show a reasonable shift compared with $\mathrm{TbF}_{4}$ as a result of the lanthanide contraction. On annealing, these two bands shift to 602.6 and $587.5 \mathrm{~cm}^{-1}$, which probably can be explained by changes in the electronic structure and a different matrix site, which is supported by the neon experiments in which this shift could not be observed because of the lower annealing temperatures. Owing to this shift, it is difficult to say whether the tetrafluoride bands also increase on annealing, but the decreasing trifluoride bands as well as the second annealing after photolysis (Figure $5 d$ ) give strong evidence for that. On photolysis, the trifluoride bands increase at the expense of the tetrafluoride ones. An additional sharp band is found at $616.0 \mathrm{~cm}^{-1}$, which does not track the tetrafluoride bands and which cannot be assigned to known impurities. As this band is not resolved from the tetrafluoride bands in the neon experiments, the behavior on annealing and photolysis cannot be determined in these experiments and the band has not been assigned. A broad feature is also found at $469 \mathrm{~cm}^{-1}$, which decreases on annealing and might increase slightly on photolysis. On the basis of the calculations described below, this can be assigned to $\left[\mathrm{DyF}_{4}\right]^{-}$. The region would also be characteristic for a difluoride, but there is no evidence for the second mode.
The Ho/ $\mathrm{F}_{2}$ spectrum shows two bands for the trifluoride at 535.8 and $556.6 \mathrm{~cm}^{-1}$, which are also reported in literature. ${ }^{[10]}$ Additional weaker bands are found at 474.7, 532.3, 546.7, 601.6 , and $616.7 \mathrm{~cm}^{-1}$, which track the trifluoride fundamentals. Although not assigned, similar bands were also observed in Knudsen cell evaporated $\mathrm{HoF}_{3}$ spectra and, thus, we assign these bands to polymer species. ${ }^{[10]}$ The behavior on annealing and photolysis of the $\mathrm{HoF}_{3}$ fundamentals is the same as that for all of the other trifluorides and there is no evidence for a possible tetrafluoride.

Further conformation for the assignment of $\mathrm{NdF}_{4}$ and $\mathrm{DyF}_{4}$ comes from experiments using neat fluorine as the matrix material, as shown in Figure 6 and Figure 7. An article describing the properties of a fluorine matrix has recently been published. ${ }^{[47,48]}$ In a neat fluorine matrix, the known tetrafluorides $\mathrm{CeF}_{4}, \mathrm{PrF}_{4}$, and $\mathrm{TbF}_{4}$ are the most stable products and the for-

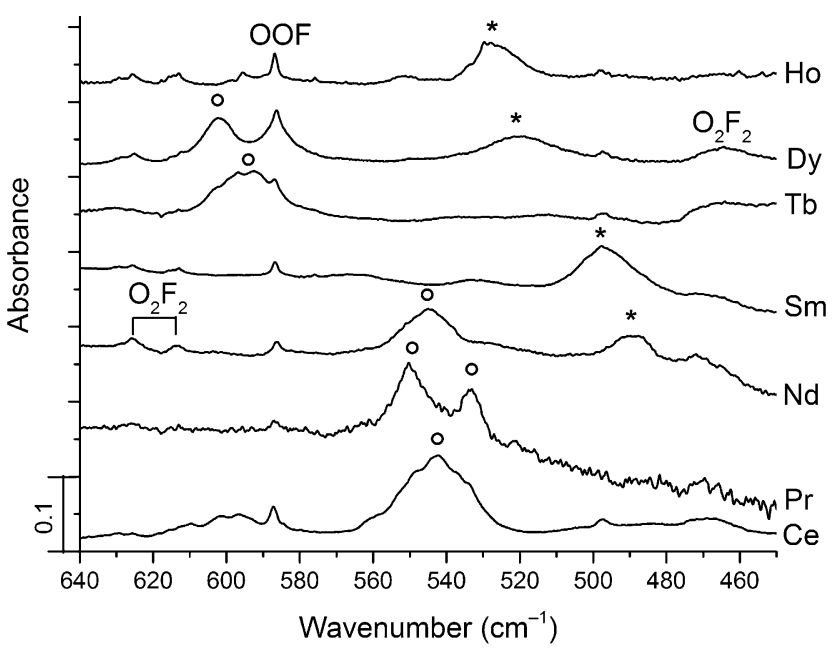

Figure 6. Reaction products of laser-ablated lanthanide atoms with $F_{2}$ in neat fluorine. Asterisks mark $\mathrm{LnF}_{3}$ compounds whereas circles mark tetrafluorides. For better comparison, some of the spectra have been scaled.

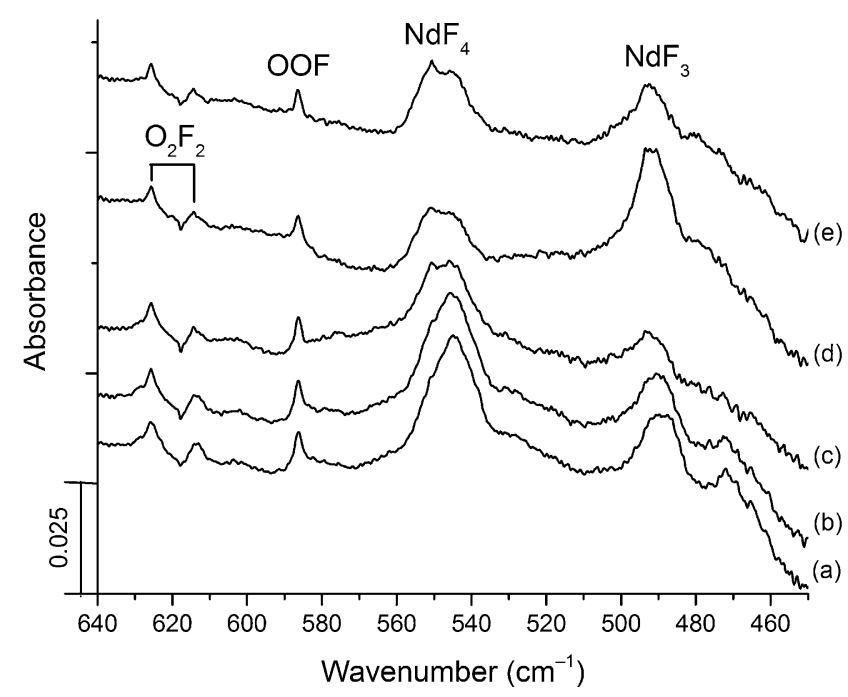

Figure 7. Reaction products of laser-ablated neodymium atoms with $F_{2}$ in neat fluorine. (a) Deposition, (b) annealing to $20 \mathrm{~K}$, (c) annealing to $28 \mathrm{~K}$ for $2 \mathrm{~min}$, (d) UV photolysis for $30 \mathrm{~min}$, (e) annealing to $30 \mathrm{~K}$. 
mation of $\mathrm{LnF}_{3}$ is not observed with these elements. For Ce and $\mathrm{Tb}$, photolysis leads again to the formation of the tetrafluoride as in the argon and neon experiments. In contrast to the argon and neon experiments where irradiation with the full mercury arc led to decomposition of $\mathrm{PrF}_{4}$ and the formation of $\mathrm{PrF}_{3}$, no significant change in the $\mathrm{PrF}_{4}$ band nor the formation of $\mathrm{PrF}_{3}$ could be observed in the fluorine matrix. On the other hand, in a fluorine matrix, Nd and Dy show significant formation of the trifluoride in addition to the tetrafluoride, indicating the lower stability of $\mathrm{NdF}_{4}$ and $\mathrm{DyF}_{4}$ (Figure 6). Again, there is no evidence for a tetrafluoride of samarium and holmium in our neat fluorine spectra.

Figure 7 shows an exemplary spectrum and the chemical behavior on annealing and photolysis of the products of laser-ablated $\mathrm{Nd}$ atoms in a neat fluorine matrix, but the $\mathrm{Dy} / \mathrm{F}_{2}$ systems are totally comparable. As expected, the tetrafluoride is formed on annealing as indicated by the decrease of the trifluoride in Figure $7 \mathrm{~b}$ and $\mathrm{c}$, which is clearly supported by the formation of the tetrafluoride on annealing in Figure $7 \mathrm{e}$. On photolysis, the tetrafluoride decomposes to the trifluoride (Figure $7 \mathrm{~d}$ ). The process of destroying the tetrafluoride on photolysis and reforming it on annealing can be cycled several times during the experiment. In these experiments the neat fluorine matrices emerge as a powerful tool to support our assignments made on the basis of the argon and neon spectra.

\section{Computational results}

The $\mathrm{LnF}_{4} /\left[\mathrm{LnF}_{4}\right]^{-}$sequence can be thought of as adding an $\mathrm{F}^{\cdot}$ radical or an $\mathrm{F}^{-}$to $\mathrm{LnF}_{3}$ and the question then exists as to whether the $\mathrm{LnF}_{3}$ will change its oxidation state on addition of the $\mathrm{F}^{*} / \mathrm{F}^{-}$. In addition, the ability to add $\mathrm{F}^{-}$is a measure of the Lewis acidity of the $\mathrm{LnF}_{3}$.

\section{Geometries}

Two additional point groups derived from the ideal $T_{d}$ point group with at least a $C_{2}$ axis and a mirror plane are possible for the $\mathrm{LnF}_{4}$ complexes: $C_{2 v}$ and $D_{2 d}$ and these are the point groups predicted for distorted molecules. The bond lengths, angles, and symmetries of the $\mathrm{LnF}_{4}$ are given in Figure 8. All of the tetrafluorides are predicted to be minima. The MP2 geometries follow, in most cases, the lanthanide contraction, which suggests that the Ln-F bonds should decrease moving from left to right across the series. The exceptions are the high spin states for $\mathrm{EuF}_{4}$ (octet), $\mathrm{GdF}_{4}$ (nonet), and the final member, $\mathrm{LuF}_{4}$. LaF $\mathrm{Li}_{4}$ is predicted to have the longest bond length of the $\mathrm{LnF}_{4}$ at $2.141 \AA$, which is consistent with the fact that it is the earliest lanthanide in the series and also cannot have an oxidation state beyond + III. It is significantly distorted from the $T_{d}$ geometry to $D_{2 d}$ symmetry with bond angles of $90^{\circ}$ and $120^{\circ}$. ${ }^{8} \mathrm{EuF}_{4}$ is slightly more stable than ${ }^{6} \mathrm{EuF}_{4}$ by $5.3 \mathrm{kcal} \mathrm{mol}^{-1}$ and ${ }^{9} \mathrm{GdF}_{4}$ is more stable than ${ }^{7} \mathrm{GdF}_{4}$ by $53.0 \mathrm{kcal} \mathrm{mol}^{-1}$. The more stable high-spin ${ }^{8} \mathrm{EuF}_{4}$ and ${ }^{9} \mathrm{GdF}_{4}$ have longer bond lengths than do the low-spin ${ }^{6} \mathrm{EuF}_{4}$ and ${ }^{7} \mathrm{GdF}_{4}$. The $\mathrm{Ln}-\mathrm{F}$ bond lengths in the low-spin ${ }^{6} \mathrm{EuF}_{4}$ and ${ }^{7} \mathrm{GdF}_{4}$ follow the lanthanide contraction. The reason for the longer bond lengths in the high-spin compounds is that they are in the + III oxidation state as discussed below. The lower spin compounds follow the lanthanide contraction because they are in the + IV oxidation state. The largest angle distortions are for ${ }^{8} \mathrm{EuF}_{4}$ with bond angles of $110^{\circ}$ between the two longer bonds and $137^{\circ}$ between the shorter bonds. The remaining molecules show smaller angular

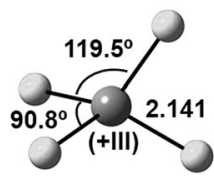

${ }^{2} \mathrm{LaF}_{4}\left(D_{2 d}\right)$

$4 f^{0.18} 5 d^{0.46}$

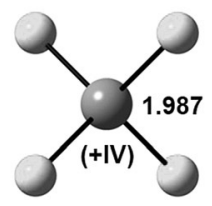

${ }^{5} \mathrm{SmF}_{4}\left(T_{d}\right)$ $4 f^{4.12} 5 d^{0.78}$

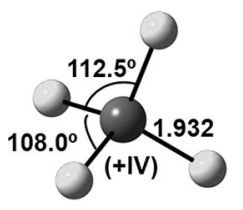

${ }^{6} \mathrm{HoF}_{4} \quad\left(D_{2 d}\right)$ $4 f^{9.03} 5 d^{0.82}$
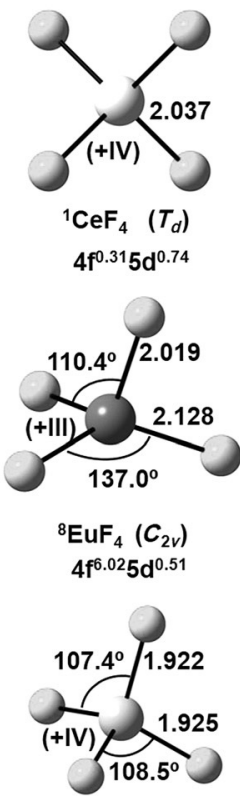

${ }^{5} \mathrm{ErF}_{4} \quad\left(C_{2 v}\right)$

$4 f^{10.02} 5 d^{0.82}$

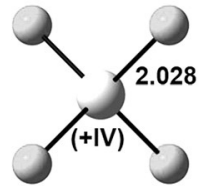

${ }^{2} \mathrm{PrF}_{4}\left(T_{d}\right)$

$4 f^{1.16} 5 d^{0.75}$

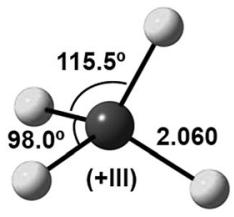

${ }^{9} \mathrm{GdF}_{4} \quad\left(D_{2 d}\right)$

$4 f^{7.02} 5 d^{0.48}$

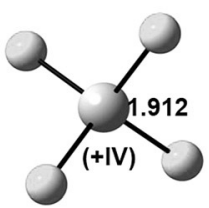

${ }^{4} \mathrm{TmF}_{4}\left(T_{d}\right)$

$4 \mathrm{f}^{11.01} 5 \mathrm{~d}^{0.83}$

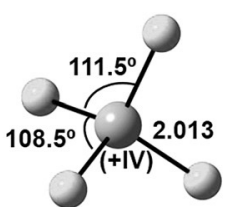

${ }^{3} \mathrm{NdF}_{4}\left(D_{2 d}\right)$ $4 f^{2.175} d^{0.77}$

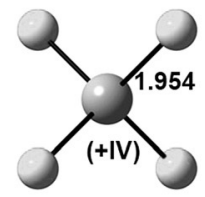

${ }^{8} \mathrm{TbF}_{4}\left(T_{d}\right)$

$4 f^{7.04} 5 d^{0.80}$

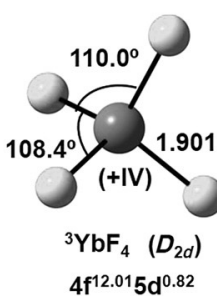

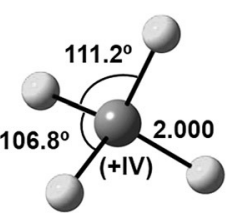

${ }^{4} \mathrm{PmF}_{4}\left(D_{2 d}\right)$

$4 f^{3.15} 5 d^{0.77}$

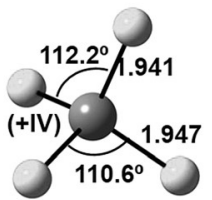

${ }^{7} \mathrm{DyF}_{4}\left(C_{2 v}\right)$

$4 f^{8.035} d^{0.80}$

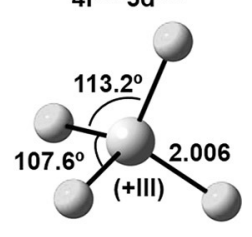

${ }^{2} \mathrm{LuF}_{4}\left(D_{2 d}\right)$

$4 f^{14} 5 d^{0.51}$

Figure 8. Geometry parameters ( $\AA$, degrees), point group, and lanthanide NPA electron configurations at the MP2 level for LnF 4 . 


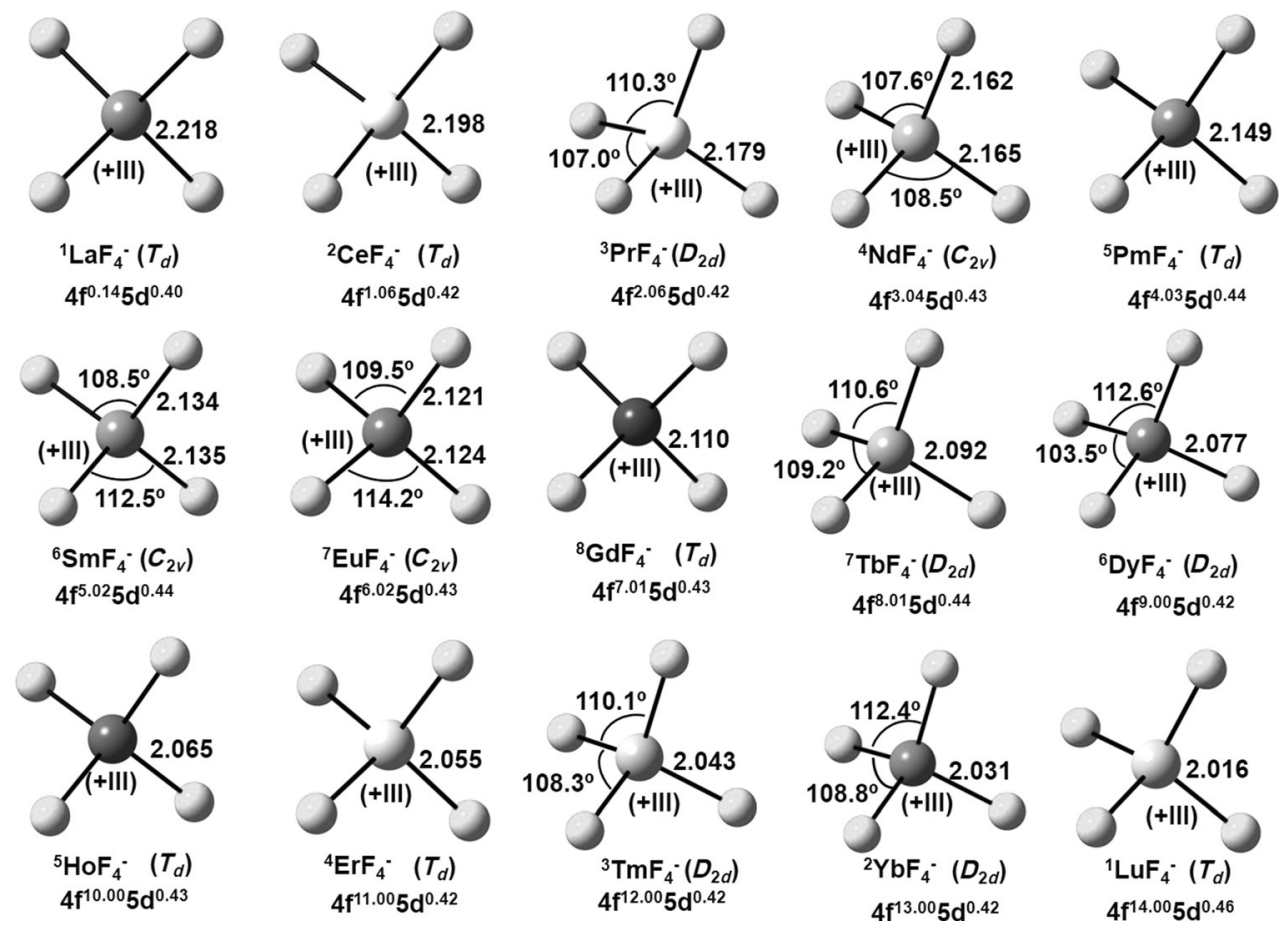

Figure 9. Geometry parameters ( $\AA$, degrees), point group, and lanthanide NPA electron configurations at the MP2 level for $\left[\mathrm{LnF}_{4}\right]^{-}$.

distortions from $\mathrm{T}_{\mathrm{d}}$ symmetry. In fact, ${ }^{3} \mathrm{NdF}_{4},{ }^{7} \mathrm{DyF}_{4},{ }^{6} \mathrm{HoF}_{4},{ }^{5} \mathrm{ErF}_{4}$ and ${ }^{3} \mathrm{YbF}_{4}$ are only slightly distorted from a $\mathrm{T}_{d}$ geometry by a few degrees. The distortions from ideal $T_{d}$ symmetry for the neutral tetrafluorides with $\mathrm{Ln}$ in the formal + III oxidation are larger than those for the tetrafluorides with $\mathrm{Ln}$ in the formal + IV oxidation state. This difference is, in part, due to one spin being on the fluorine atoms and more ionic Ln-F bonds.

The anionic complexes have longer bonds than their neutral counterparts. The anionic complexes (Figure 9) mostly follow the lanthanide contraction. For these complexes, $\left[\mathrm{LaF}_{4}\right]^{-}$has the longest bond length with $\left[\mathrm{LuF}_{4}\right]^{-}$having the shortest. Unlike the neutral complexes, all the geometries for the anionic complexes are tetrahedral or slightly distorted tetrahedral structures.

\section{Vibrational frequencies}

The neutral complexes follow the lanthanide contraction for the Ln-F bond lengths, except for high-spin ${ }^{8} \mathrm{EuF}_{4}$ and ${ }^{9} \mathrm{GdF}_{4}$. Thus, we would expect a trend of increasing stretching frequencies as the atomic number increases across the series. Excluding the exceptions, the symmetric stretching frequencies of the $\mathrm{LnF}_{4}$ (Table 1) derived from the $\mathrm{a}_{1}$ stretch in $\mathrm{T}_{\mathrm{d}}$ symmetry show the trend of increasing frequencies. As long as the distortion from the $T_{d}$ structure is not too large, the $t_{2}$ asymmetric stretching frequencies do not exhibit a large splitting. We averaged the frequencies derived from the $t_{2} T_{d}$ mode, as they are not split by very much, for ${ }^{3} \mathrm{NdF}_{4},{ }^{4} \mathrm{PmF}_{4},{ }^{6} \mathrm{EuF}_{4},{ }^{7} \mathrm{DyF}_{4},{ }^{6} \mathrm{HoF}_{4}$ ${ }^{5} \mathrm{ErF}_{4}$, and ${ }^{3} \mathrm{YbF}_{4}$ and obtained the values 597, 606, 615, 642, 649,666 , and $678 \mathrm{~cm}^{-1}$, which fit the expected lanthanide contraction pattern when combined with the other results for the $\mathrm{T}_{\mathrm{d}}$ molecules. ${ }^{2} \mathrm{LaF}_{4},{ }^{8} \mathrm{EuF}_{4},{ }^{7} \mathrm{GdF}_{4},{ }^{9} \mathrm{GdF}_{4}$, and ${ }^{2} \mathrm{LuF}_{4}$ exhibit large splittings of the asymmetric bands so we cannot average their values. Excluding ${ }^{7} \mathrm{GdF}_{4}$, these latter fluorides have the $\mathrm{Ln}$ in the + III oxidation state and the distortions from $T_{d}$ geometries are the largest. We note that prior calculations ${ }^{[50]}$ of the stretching modes for $\mathrm{CeF}_{4}$ at the MP2 level with a different basis set are within a few $\mathrm{cm}^{-1}$ of the current values.

Good agreement with the experimental matrix results is found for $\mathrm{LnF}_{2}$ and $\mathrm{LnF}_{3}$, showing the validity of the computational approach (see the Supporting Information). The $\mathrm{LnF}_{3}$ species previously reported at the DFT level are all within $30 \mathrm{~cm}^{-1}$ of experiment, except for $\mathrm{PrF}_{3}$ where the calculated values differed from experiment by $\approx 50 \mathrm{~cm}^{-1}$. The calculated values do not contain anharmonic corrections and the experimental values should be smaller than those predicted. For the $\mathrm{LnF}_{4}$, good agreement with the assigned asymmetric stretches is found for ${ }^{1} \mathrm{CeF}_{4}$ (within $10 \mathrm{~cm}^{-1}$ ), ${ }^{2} \mathrm{PrF}_{4}$ (within $10 \mathrm{~cm}^{-1}$ of the Ne results), ${ }^{8} \mathrm{TbF}_{4}$ (within $15 \mathrm{~cm}^{-1}$ ), ${ }^{7} \mathrm{DyF}_{4}$ (within $15 \mathrm{~cm}^{-1}$ ), and for ${ }^{3} \mathrm{NdF}_{4}$ (within $\approx 30 \mathrm{~cm}^{-1}$ ). The experimental $\mathrm{NdF}_{4}$ results may not be consistent with the Ln contraction.

We include some of the B3LYP results for the $\mathrm{LnF}_{4}$ in Table 1 for the cases in which spin contamination was not too large. The DFT B3LYP Ln-F bond lengths are predicted to be longer than the MP2 values so the predicted frequencies are smaller. In general, there is significant spin contamination at the density functional theory level with the B3LYP functional and it is difficult to get good agreement with experiment. This seems to arise from too much mixing of the + III and + IV oxidation states as well as too much back-bonding into the $4 \mathrm{f}$ orbitals from the ligands.

Consistent with the bond lengths, the vibrational frequencies for $\left[\mathrm{LnF}_{4}\right]^{-}$show the lanthanide contraction (Figure 9). The symmetric stretching frequencies show a constant and gradual 
increase as we move across the lanthanide row. The bond lengths are significantly longer in $\left[\mathrm{LnF}_{4}\right]^{-}$than in $\mathrm{LnF}_{4}$ and, as a consequence, the corresponding $\mathrm{Ln}-\mathrm{F}$ stretching frequencies are significantly lower in the anions. The results in Table 2 show much better agreement between the MP2 and B3LYP values.

\begin{tabular}{|c|c|c|c|c|c|c|}
\hline$\left[\mathrm{LnF}_{4}\right]^{-}$ & $\begin{array}{l}\text { Point } \\
\text { group }^{[a]}\end{array}$ & $\begin{array}{l}\text { Sym. } \\
v \text { MP2 }\end{array}$ & $\begin{array}{l}\text { Asym. } \\
v \text { MP2 }\end{array}$ & $\begin{array}{l}r \\
\text { (Ln-F) } \\
\text { B3LYP }\end{array}$ & $\begin{array}{l}\text { Sym. } \\
v(\mathrm{I}) \\
\text { B3LYP }\end{array}$ & $\begin{array}{l}\text { Asym. } \\
v(\mathrm{I}) \\
\text { B3LYP }\end{array}$ \\
\hline \multirow{2}{*}{$\begin{array}{l}\left.{ }^{1} \mathrm{LaF}_{4}\right]^{-} \\
\left.{ }^{2} \mathrm{CeF}_{4}\right]^{-}\end{array}$} & $T_{d}$ & $\begin{array}{l}465.8 \\
\left(a_{1}\right)\end{array}$ & $\begin{array}{l}422.9 \\
\left(\mathrm{t}_{2}\right)\end{array}$ & 2.213 & $\begin{array}{l}454.0 \\
a_{1}(0)\end{array}$ & $\begin{array}{l}411.4 \\
t_{2}(640)\end{array}$ \\
\hline & $T_{d} / C_{2 v}$ & $\begin{array}{l}470.1 \\
\left(a_{1}\right)\end{array}$ & $\begin{array}{l}433.0 \\
\left(t_{2}\right)\end{array}$ & $2.184 \times 2$ & $469.9(0)$ & $\begin{array}{l}429.8(213) \\
429.0(209) \\
421.5(189)\end{array}$ \\
\hline$\left.{ }^{3} \mathrm{PrF}_{4}\right]^{-}$ & $D_{2 d} / C_{2 v}$ & 478.2 & $\begin{array}{l}440.7 \\
(\mathrm{e}) \\
442.8\end{array}$ & $2.171 \times 2$ & $473.4(0)$ & $\begin{array}{l}436.6(237) \\
429.4(200)\end{array}$ \\
\hline$\left[{ }^{4} \mathrm{NdF}_{4}\right]^{-}$ & $C_{2 v} / T_{d}$ & 483.9 & $\begin{array}{l}447.2 \\
\\
448.4 \\
448.7\end{array}$ & 2.160 & $\begin{array}{l}478.4, \\
a_{1}(0)\end{array}$ & $\begin{array}{l}443.1 \\
t_{2}(614)\end{array}$ \\
\hline$\left[\mathrm{PmF}_{4}\right]^{-}$ & $T_{d}$ & $\begin{array}{l}488.2 \\
\left(a_{1}\right)\end{array}$ & $\begin{array}{l}452.2 \\
\left(t_{2}\right)\end{array}$ & 2.145 & $\begin{array}{l}487.8, a_{1} \\
(0)\end{array}$ & $\begin{array}{l}454.1, t_{2} \\
(617)\end{array}$ \\
\hline$\left[{ }^{6} \mathrm{SmF}_{4}\right]^{-}$ & $C_{2 v}$ & 494.2 & $\begin{array}{l}455.4 \\
456.9 \\
466.5\end{array}$ & $\begin{array}{l}2.131 \times 2 \\
2.137 \times 2\end{array}$ & 488.8 (1) & $\begin{array}{l}453.9(199) \\
452.9(194) \\
449.5(186)\end{array}$ \\
\hline$\left.{ }^{7} \mathrm{EuF}_{4}\right]^{-}$ & $C_{2 v}$ & 498.3 & $\begin{array}{l}461.1 \\
464.1 \\
468.4\end{array}$ & $\begin{array}{l}2.122 \times 2 \\
2.124 \times 2\end{array}$ & 491.9 (1) & $\begin{array}{l}496.3(192) \\
455.1(184) \\
452.2(165)\end{array}$ \\
\hline$\left[{ }^{8} \mathrm{GdF}_{4}\right]^{-}$ & $T_{d}$ & $\begin{array}{l}502.0 \\
\left(a_{1}\right)\end{array}$ & $\begin{array}{l}467.0 \\
\left(t_{2}\right)\end{array}$ & 2.126 & $\begin{array}{l}473.9, a_{1} \\
(0)\end{array}$ & $\begin{array}{l}448.0, t_{2} \\
(440)\end{array}$ \\
\hline$\left.{ }^{7} \mathrm{TbF}_{4}\right]^{-}$ & $D_{2 d} / T_{d}$ & 506.8 & $\begin{array}{l}480.1 \\
473.4 \\
(\mathrm{e})\end{array}$ & 2.092 & $501.6(0)$ & $\begin{array}{l}465.9, \mathrm{t}_{2} \\
(524)\end{array}$ \\
\hline \multirow[t]{2}{*}[{}^{6}\mathrm{DyF}_{4}]{$^{-}$} & $D_{2 d} / C_{2 v}$ & 511.9 & $\begin{array}{l}471.5 \\
\text { (e) } \\
483.6\end{array}$ & $\begin{array}{l}2.081 \times 2 \\
2.085 \times 2\end{array}$ & $500.7(1)$ & $\begin{array}{l}471.1(187) \\
467.3(162)\end{array}$ \\
\hline & & & & & & 464.5 (166) \\
\hline \multirow[t]{2}{*}[{}^{5}\mathrm{HoF}_{4}]{$^{-}$} & $T_{d} / C_{2 v}$ & $\begin{array}{l}513.7 \\
\left(a_{1}\right)\end{array}$ & $\begin{array}{l}481.1 \\
\left(t_{2}\right)\end{array}$ & $2.079 \times 2$ & $509.6(2)$ & 478.1 (177) \\
\hline & & & & $2.074 \times 2$ & & $\begin{array}{l}477.3(166) \\
473.8(154)\end{array}$ \\
\hline \multirow[t]{2}{*}[{}^{4}\mathrm{ErF}_{4}]{$^{-}$} & $T_{d} / C_{2 v}$ & 516.2 & $\begin{array}{l}488.3 \\
\left(t_{2}\right)\end{array}$ & $2.065 \times 2$ & $511.6(2)$ & $486.4(178)$ \\
\hline & & & & $2.067 \times 2$ & & $\begin{array}{l}481.9(148) \\
479.9(152)\end{array}$ \\
\hline \multirow[t]{2}{*}[{}^{3}\mathrm{TmF}_{4}]{$^{-}$} & $D_{2 d} / C_{2 v}$ & 520.6 & $\begin{array}{l}493.4 \\
\text { (e) }\end{array}$ & $2.050 \times 2$ & $515.1(8)$ & 486.9 (147) \\
\hline & & & 494.0 & $2.059 \times 2$ & & $\begin{array}{l}485.1(155) \\
483.3(158)\end{array}$ \\
\hline$\left[{ }^{2} \mathrm{YbF}_{4}\right]^{-}$ & $D_{2 d}$ & 524.3 & $\begin{array}{l}496.2 \\
(\mathrm{e}) \\
504.4\end{array}$ & 2.043 & $518.4(0)$ & $\begin{array}{l}500.3(158) \\
488.2 \\
\text { e (289) }\end{array}$ \\
\hline$\left[^{1} \mathrm{LuF}_{4}\right]^{-}$ & $T_{d}$ & $\begin{array}{l}531.8 \\
\left(a_{1}\right)\end{array}$ & $\begin{array}{l}505.8 \\
\left(\mathrm{t}_{2}\right)\end{array}$ & 2.031 & $\begin{array}{l}525.7, \\
a_{1}(0)\end{array}$ & $\begin{array}{l}500.8 \\
t_{2}(452)\end{array}$ \\
\hline
\end{tabular}

\section{Population analysis}

A natural population analysis (NPA) using the natural bond orbitals (NBOs) was performed to analyze the electron configurations of the lanthanides. There is minimal spin contamination for most compounds at the MP2 level. The spin densities are shown in the Supporting Information. The data for the $\mathrm{LnF}_{4}$ in Table 3 show that $\mathrm{La}^{\mathrm{II}} \mathrm{F}_{4}$ and $\mathrm{Lu}^{\text {III }} \mathrm{F}_{4}$ have doublet spin states

\begin{tabular}{|c|c|c|c|c|c|c|c|}
\hline $\mathrm{LnF}_{4}$ & $\mathrm{~S}^{2} /\left\langle\mathrm{S}^{2}\right\rangle$ & $\begin{array}{l}\text { Ln } \\
\text { excess } \\
\text { spin }\end{array}$ & $\begin{array}{l}\text { Ln } \\
\text { oxidation } \\
\text { state }\end{array}$ & $\begin{array}{l}\operatorname{Ln} 4 \mathrm{f} \\
\alpha\end{array}$ & $\begin{array}{l}\operatorname{Ln} 5 d \\
\alpha\end{array}$ & $\begin{array}{l}\text { Pop } \\
2 p F\end{array}$ & $\begin{array}{l}F 2 p \\
\alpha-\beta\end{array}$ \\
\hline${ }^{2} \mathrm{LaF}_{4}$ & $0.81 / 0.75$ & & + III & 0.08 & 0.18 & $2 p^{5.65}$ & 0.25 \\
\hline${ }^{1} \mathrm{CeF}_{4}$ & $0.00 / 0.00$ & & $+\mathrm{IV}$ & & & $2 p^{5.77}$ & 0 \\
\hline${ }^{2} \mathrm{PrF}_{4}$ & $0.75 / 0.75$ & $4 f^{1}$ & $+\mathrm{IV}$ & 1.06 & 0.38 & $2 p^{5.77}$ & 0 \\
\hline${ }^{3} \mathrm{NdF}_{4}$ & $2.00 / 2.00$ & $4 f^{2}$ & $+\mathrm{IV}$ & 2.06 & 0.39 & $2 p^{5.76}$ & 0 \\
\hline${ }^{4} \mathrm{PmF}_{4}$ & $3.75 / 3.75$ & $4 f^{3}$ & $+\mathrm{IV}$ & 3.05 & 0.40 & $2 p^{5.78}$ & 0 \\
\hline${ }^{5} \mathrm{SmF}_{4}$ & $6.01 / 6.00$ & $4 f^{4}$ & $+\mathrm{IV}$ & 4.04 & 0.41 & $2 p^{5.79}$ & 0 \\
\hline${ }^{6} \mathrm{EuF}_{4}$ & $8.76 / 8.75$ & $4 f^{5}$ & $+\mathrm{IV}$ & 5.04 & 0.41 & $2 p^{5.79}$ & 0 \\
\hline${ }^{8} \mathrm{EuF}_{4}$ & $15.82 / 15.75$ & $4 f^{6}$ & + III & 6.00 & 0.23 & $2 p^{5.42 / 5.85}$ & $0.52 / 0$ \\
\hline${ }^{7} \mathrm{GdF}_{4}$ & $12.01 / 12.00$ & $4 f^{6}$ & $+\mathrm{IV}$ & 6.03 & 0.43 & $2 p^{5.80}$ & 0 \\
\hline${ }^{9} \mathrm{GdF}_{4}$ & $20.05 / 20.00$ & $4 f^{7}$ & + III & 7.00 & 0.20 & $2 p^{5.65}$ & 0.25 \\
\hline${ }^{8} \mathrm{TbF}_{4}$ & $15.76 / 15.75$ & $4 f^{7}$ & + IV & 7.00 & 0.43 & $2 p^{5.80}$ & 0 \\
\hline${ }^{7} \mathrm{DyF}_{4}$ & $12.01 / 12.00$ & $4 f^{6}$ & $+\mathrm{IV}$ & 7.00 & 0.42 & $2 p^{5.80}$ & 0 \\
\hline${ }^{6} \mathrm{HoF}_{4}$ & $8.76 / 8.75$ & $4 f^{5}$ & $+\mathrm{IV}$ & 7.00 & 0.43 & $2 p^{5.80}$ & 0 \\
\hline${ }^{5} \mathrm{ErF}_{4}$ & $6.01 / 6.00$ & $4 f^{4}$ & $+\mathrm{IV}$ & 7.00 & 0.43 & $2 p^{5.80}$ & 0 \\
\hline${ }^{4} \mathrm{TmF}_{4}$ & $3.75 / 3.75$ & $4 f^{3}$ & $+\mathrm{IV}$ & 7.00 & 0.42 & $2 p^{5.80}$ & 0 \\
\hline${ }^{3} \mathrm{YbF}_{4}$ & $2.00 / 2.00$ & $4 f^{2}$ & $+\mathrm{IV}$ & 7.00 & 0.42 & $2 p^{5.80}$ & 0 \\
\hline${ }^{2} \mathrm{LuF}_{4}$ & $0.82 / 0.75$ & & $+I I I$ & 7.00 & 0.19 & $2 p^{5.63}$ & 0.29 \\
\hline
\end{tabular}

with the one spin on the fluorine atoms as the $f$ orbitals are formally empty or completely filled; these end point limiting cases are in the + III oxidation state. Most of the remaining Ln are in the +IV oxidation state with all of the spin localized on the Ln. Except for high-spin ${ }^{8} \mathrm{EuF}_{4}$ and ${ }^{9} \mathrm{GdF}_{4}$, there is $\approx 0.8 \mathrm{e}$ in the $d$ orbitals, which is predominantly spin paired. This represents back-donation from the $F$ ligands to the Ln. There is a small amount of back-bonding into the $4 \mathrm{f}$ orbitals on most of the $\operatorname{Ln}$ up to $0.3 \mathrm{e}$. The largest back-bonding to the $4 \mathrm{f}$ orbital is for Ce. There is very little back-bonding to the $4 \mathrm{f}$ orbital past $\mathrm{Sm}$. For the high-spin ${ }^{8} \mathrm{EuF}_{4}$ and ${ }^{9} \mathrm{GdF}_{4}$, there is substantially less back-bonding to the $5 \mathrm{~d}$ orbitals from the $\mathrm{F}$ atoms with only $\approx 0.5 \mathrm{e}$ in the $5 \mathrm{~d}$ orbitals. For the high-spin ${ }^{8} \mathrm{EuF}_{4}$ and ${ }^{9} \mathrm{GdF}_{4}$, the oxidation state is + III, with one unpaired spin on the $\mathrm{F}$ atoms, which is either fully shared on all four atoms as in ${ }^{9} \mathrm{GdF}_{4},{ }^{2} \mathrm{LaF}_{4}$, and ${ }^{2} \mathrm{LuF}_{4}$, or localized on two $\mathrm{F}$ atoms as in ${ }^{8} \mathrm{EuF}_{4}$. For high-spin ${ }^{8} \mathrm{EuF}_{4}$, the molecule has a $4 \mathrm{f}^{6}$ open-shell configuration on the Eu. For ${ }^{9} \mathrm{GdF}_{4}$, the $\mathrm{Gd}$ has a $4 \mathrm{f}^{7}$ configuration. Thus, for these two high-spin cases where it is possible to attain a half-filled or close to half-filled shell, the tetrafluoride prefers the + III oxidation state. We note that this preference is only by $4 \mathrm{kcalmol}^{-1}$ for $\mathrm{EuF}_{4}$, which does not attain the $4 \mathrm{f}^{7}$ electronic configuration.

The NBO analysis shows that the $\mathrm{Ln}-\mathrm{F}$ bonds are highly ionic. For $\mathrm{LnF}_{4}$ with $\mathrm{Ln}$ in the formal + III oxidation state $(\mathrm{Ln}=$ $\mathrm{La}, \mathrm{Eu}, \mathrm{Gd}, \mathrm{Lu}$ ), the Ln-F bond is almost completely ionic and there is an excess spin density on the fluorine atoms. For $\mathrm{LnF}_{4}$ 
with $\mathrm{Ln}$ in the formal + IV oxidation state, there is only $6-8 \%$ of the population on the $\mathrm{Ln}$. The $\mathrm{Ln}$ contribution has $\approx 30 \%$ from the $4 \mathrm{f}$ orbitals and $64 \%$ from the $5 \mathrm{~d}$ orbitals with $\approx 6 \%$ from the $6 \mathrm{~s}$ orbital for $\mathrm{Ce}, \mathrm{Pr}$, and $\mathrm{Nd}$. For $\mathrm{PmF}_{4}$, the participation of $\mathrm{Pm} 4 \mathrm{f}$ electrons drops to $12 \%$ and further drops to $3-$ $7 \%$ for the remaining $\mathrm{Ln}^{\mathrm{IV}}$. The majority valence orbital contribution of $\approx 70 \%$ is from the $\mathrm{Ln} 5 \mathrm{~d}$ orbitals and the remainder is from the $6 \mathrm{~s}$.

In contrast, the B3LYP calculation results have more $4 \mathrm{f}$ orbital character than do the MP2 calculations with the $4 \mathrm{f}$ orbitals being involved in the back-bonding from the $F$ ligands. This could be the cause of some of the difficulties with spin contamination in the open-shell calculations. The significant spin contamination can arise as the Ln tries to mix different electron occupancies and oxidation states.

The NPA data for the anions are given in Table 4. In this case, all of the anions are in the + III oxidation state. There is no excess spin on any of the $\mathrm{F}$ atoms in contrast to the neutral compounds. Thus, when an electron is added to $\mathrm{LnF}_{4}$, it goes into an $\mathrm{f}$ orbital on the $\mathrm{Ln}$ if it is available.

\begin{tabular}{|c|c|c|c|c|c|c|}
\hline$\left[\mathrm{LnF}_{4}\right]^{-}$ & $\mathrm{S}^{2} /<\mathrm{S}^{2}>$ & $\begin{array}{l}\text { Ln } \\
\text { excess } \\
\text { spin }\end{array}$ & $\begin{array}{l}\text { Ln } \\
\text { oxidation } \\
\text { state }\end{array}$ & $\operatorname{Ln} 4 f \alpha$ & $\operatorname{Ln} 5 d \alpha$ & Pop 2p F \\
\hline$\left[{ }^{1} \mathrm{LaF}_{4}\right]^{-}$ & $0.00 / 0.00$ & & + III & & & $2 p^{5.89}$ \\
\hline$\left[{ }^{2} \mathrm{CeF}_{4}\right]^{-}$ & $0.75 / 0.75$ & $4 f^{1}$ & + III & 1.02 & 0.21 & $2 p^{5.88}$ \\
\hline$\left[{ }^{3} \mathrm{PrF}_{4}\right]^{-}$ & $2.00 / 2.00$ & $4 f^{2}$ & + III & 2.02 & 0.22 & $2 p^{5.89}$ \\
\hline$\left[{ }^{4} \mathrm{NdF}_{4}\right]^{-}$ & $3.75 / 3.75$ & $4 f^{3}$ & + III & 3.01 & 0.22 & $2 p^{5.90}$ \\
\hline$\left[{ }^{5} \mathrm{PmF}_{4}\right]^{-}$ & $6.00 / 6.00$ & $4 f^{4}$ & + III & 4.01 & 0.23 & $2 p^{5.90}$ \\
\hline$\left[{ }^{6} \mathrm{SmF}_{4}\right]^{-}$ & $8.76 / 8.75$ & $4 f^{5}$ & + III & 5.00 & 0.23 & $2 p^{5.90}$ \\
\hline$\left[{ }^{7} \mathrm{EuF}_{4}\right]^{-}$ & $12.00 / 12.00$ & $4 f^{6}$ & + III & 6.00 & 0.23 & $2 p^{5.90}$ \\
\hline$\left[{ }^{8} \mathrm{GdF}_{4}\right]^{-}$ & $15.76 / 15.75$ & $4 f^{7}$ & + III & 7.00 & 0.23 & $2 p^{5.90}$ \\
\hline$\left[{ }^{7} \mathrm{TbF}_{4}\right]^{-}$ & $12.01 / 12.00$ & $4 f^{6}$ & + III & 7.00 & 0.23 & $2 p^{5.90}$ \\
\hline$\left[{ }^{6} \mathrm{DyF}_{4}\right]^{-}$ & $8.76 / 8.75$ & $4 f^{5}$ & + III & 7.00 & 0.22 & $2 p^{5.90}$ \\
\hline$\left[{ }^{5} \mathrm{HoF}_{4}\right]^{-}$ & $6.00 / 6.00$ & $4 f^{4}$ & + III & 7.00 & 0.22 & $2 p^{5.90}$ \\
\hline$\left[{ }^{4} \mathrm{ErF}_{4}\right]^{-}$ & $3.75 / 3.75$ & $4 f^{3}$ & + III & 7.00 & 0.22 & $2 p^{5.90}$ \\
\hline$\left[{ }^{3} \mathrm{TmF}_{4}\right]^{-}$ & $2.00 / 2.00$ & $4 f^{2}$ & + III & 7.00 & 0.21 & $2 p^{5.90}$ \\
\hline$\left[{ }^{2} \mathrm{YbF}_{4}\right]^{-}$ & $0.75 / 0.75$ & $4 f^{1}$ & + III & 7.00 & 0.21 & $2 p^{5.90}$ \\
\hline$\left[{ }^{1} \mathrm{LuF}_{4}\right]^{-}$ & $0.00 / 0.00$ & & + III & & & $2 p^{5.89}$ \\
\hline
\end{tabular}

\section{Reaction energies}

Various energy quantities are summarized in Table 5. The electron affinities of the $\mathrm{LnF}_{4}$ are, in general, very high, showing that these compounds will be excellent oxidizing agents. These electron affinities range from $2.67-9.65 \mathrm{eV}$, and some of these electron affinities are extraordinarily high, substantially larger than the electron affinity range of the halogen atoms (3.0-3.6 eV). These high electron affinities suggest that the most of the neutral $\mathrm{LnF}_{4}$ complexes can act as enhanced oxidizing agents. $\mathrm{CeF}_{4}$ has the lowest electron affinity owing to it being a closed-shell singlet. The electron affinities increase from $\mathrm{CeF}_{4}$ to $\mathrm{EuF}_{4}$. Most of the remaining electron affinities are in the 6.0 to $10.0 \mathrm{eV}$ range, except for $\mathrm{TbF}_{4}$ and $\mathrm{DyF}_{4}$ with lower electron affinities near $4 \mathrm{eV}$. $\mathrm{TbF}_{4}$ has a stabilized, completely half-full subshell so the neutral species is more stable,
Table 5. Calculated electron affinities, fluoride affinities, $F_{2}$ elimination energies, and Ln-F BDE at the MP2/Stuttgart/aug-cc-pVDZ level.

\begin{tabular}{|c|c|c|c|c|}
\hline $\mathrm{LnF}_{4}$ & $\begin{array}{l}\text { Electron } \\
\text { affinity } \\
{[\mathrm{eV}]} \\
(0 \mathrm{~K})\end{array}$ & $\begin{array}{l}\text { Fluoride affinity } \\
\mathrm{LnF}_{3}+\mathrm{F}^{-} \rightarrow \\
{\left[\mathrm{LnF}_{4}\right]^{-}} \\
{\left[\mathrm{kcal} \mathrm{mol}^{-1}\right]} \\
(298 \mathrm{~K})\end{array}$ & $\begin{array}{l}\mathrm{F}_{2} \text { elimination } \\
\mathrm{LnF}_{4} \rightarrow \\
\mathrm{LnF}_{2}+\mathrm{F}_{2} \\
{\left[\mathrm{kcal} \mathrm{mol}^{-1}\right]} \\
(298 \mathrm{~K})\end{array}$ & $\begin{array}{l}\mathrm{Ln}-\mathrm{F} \mathrm{BDE} \\
\mathrm{LnF}_{4} \rightarrow \\
\mathrm{LnF}_{3}+\mathrm{F} \\
{\left[\mathrm{kcal} \mathrm{mol}^{-1}\right]} \\
(298 \mathrm{~K})\end{array}$ \\
\hline${ }^{2} \mathrm{LaF}_{4}$ & 7.78 & 97.1 & 124.4 & -0.5 \\
\hline${ }^{1} \mathrm{CeF}_{4}$ & 2.67 & 93.3 & 268.3 & 113.8 \\
\hline${ }^{2} \mathrm{PrF}_{4}$ & 4.91 & 94.2 & 205.1 & 62.9 \\
\hline${ }^{3} \mathrm{NdF}_{4}$ & 6.38 & 94.7 & 153.2 & 29.6 \\
\hline${ }^{4} \mathrm{PmF}_{4}$ & 7.05 & 103.3 & 145.9 & 22.7 \\
\hline${ }^{5} \mathrm{SmF}_{4}$ & 7.43 & 100.6 & 133.3 & 11.3 \\
\hline${ }^{8} \mathrm{EuF}_{4}{ }^{[\mathrm{a]}]}$ & 8.48 & 100.8 & 56.1 & -12.9 \\
\hline${ }^{9} \mathrm{GdF}_{4}$ & 8.20 & 106.0 & 113.3 & -1.5 \\
\hline${ }^{8} \mathrm{TbF}_{4}$ & 3.99 & 104.3 & $279.4^{[b]}$ & 94.5 \\
\hline${ }^{7} \mathrm{DyF}_{4}$ & 3.94 & 84.7 & $174.1^{[\mathrm{b}]}$ & 76.0 \\
\hline${ }^{6} \mathrm{HoF}_{4}$ & 6.04 & 87.5 & 134.7 & 30.3 \\
\hline${ }^{5} \mathrm{ErF}_{4}$ & 8.10 & 111.7 & 120.3 & 7.0 \\
\hline${ }^{4} \mathrm{TmF}_{4}$ & 8.21 & 108.3 & 82.6 & 1.0 \\
\hline${ }^{3} \mathrm{YbF}_{4}$ & 9.65 & 107.6 & 22.4 & -32.7 \\
\hline${ }^{2} \mathrm{LuF}_{4}$ & 8.52 & 112.6 & 119.1 & -2.3 \\
\hline $\begin{array}{l}\text { [a] For } \\
-17.9 \mathrm{k} \\
\mathrm{DyF}_{2} \text {. }\end{array}$ & $\begin{array}{l}\mathrm{F}_{4}, \mathrm{EA}= \\
\mathrm{Imol}^{-1} .\end{array}$ & $\begin{array}{l}71 \mathrm{eV}, E\left(\mathrm{~F}_{2} \text { elimir }\right. \\
\text { There is signific }\end{array}$ & $\begin{array}{l}\mathrm{n})=51.1 \mathrm{kcal} \\
\text { pin contamin }\end{array}$ & $\begin{array}{l}-1, \mathrm{Ln}-\mathrm{F} \mathrm{BC} \\
\text { on for } \mathrm{TbF}_{2}\end{array}$ \\
\hline
\end{tabular}

lowering the electron affinity. $\mathrm{DyF}_{4}$ may be starting a new sequence like $\mathrm{PrF}_{4}$.

The $\mathrm{Ln}-\mathrm{F}$ bond dissociation energies (BDEs) are probably lower than expected owing to the use of MP2 to calculate these values. The only available data is for the average BDE of $\mathrm{CeF}_{4}$, which is $144 \mathrm{kcal} \mathrm{mol}^{-1} .^{[50]}$ The highest $\mathrm{Ln}-\mathrm{F}$ BDE belongs to $\mathrm{CeF}_{4}$, because $\mathrm{CeF}_{4}$ is a closed-shell singlet in its ground state. ${ }^{2} \mathrm{LaF}_{4},{ }^{8} \mathrm{EuF}_{4},{ }^{9} \mathrm{GdF}_{4},{ }^{3} \mathrm{YbF}_{4}$, and ${ }^{2} \mathrm{LuF}_{4}$ are predicted to have negative BDEs. Even if there is an error at the MP2 level, these BDEs will still be low. For $\mathrm{LaF}_{4}$, the Ln cannot attain the + IV oxidation state so the BDE should be small or near zero, as found. Again, ${ }^{8} \mathrm{EuF}_{4}$ and ${ }^{9} \mathrm{GdF}_{4}$ have the $\mathrm{Ln}$ in the + III oxidation state and they do not want to bind the additional $\mathrm{F}$ to $\mathrm{LnF}_{3}$. $\mathrm{CeF}_{4}, \mathrm{PrF}_{4}, \mathrm{NdF}_{4}, \mathrm{TbF}_{4}$, and $\mathrm{DyF}_{4}$ have all been observed. In this group of tetrafluorides, except for $\mathrm{NdF}_{4}$, all of the predicted Ln-F BDEs are substantial consistent with the observation of these compounds. The $\mathrm{NdF}_{4} \mathrm{BDE}$ near $30 \mathrm{kcalmol}^{-1}$ must be just enough for the compound to be stable as it has been observed. In contrast, $\mathrm{SmF}_{4}$ with $\mathrm{a} \approx 20 \mathrm{kcal} \mathrm{mol}^{-1}$ lower BDE was not observed. The calculated results suggest that $\mathrm{HoF}_{4}$ might be possible to observe.

The $F_{2}$ elimination reaction energies show that many of these compounds should be very stable with respect to loss of $F_{2}$ to form $L_{n} F_{2}$ with the $\mathrm{Ln}$ in the + Il oxidation state. The highest $\mathrm{F}_{2}$ elimination belongs to $\mathrm{CeF}_{4}$ because $\mathrm{Ce}^{\mathrm{IV}}$ is a closed-shell singlet and requires more energy to remove fluorine and produce the less stable + II oxidation state. The lowest $F_{2}$ elimination reaction energy belongs to $\mathrm{YbF}_{4}$, which is consistent with the negative $\mathrm{Yb}-\mathrm{F}$ BDE. $\mathrm{EuF}_{4}$ is also predicted to be not very stable with respect to loss of $F_{2}$, again consistent with the Eu-F BDE. 


\section{Conclusion}

We report the matrix-isolated reaction products of laser-ablated lanthanide atoms with fluorine in excess neon and argon. Our argon and neon experimental results are supported by experiments in neat fluorine matrices. Besides the known tetrafluorides of $\mathrm{Ce}, \mathrm{Pr}$, and $\mathrm{Tb}$, the new neutral $\mathrm{NdF}_{4}$ and $\mathrm{DyF}_{4}$ molecules were observed and characterized by IR spectroscopy. There is no evidence of tetrafluoride formation for $\mathrm{Sm}$ and Ho. This is consistent with the low Sm-F BDEs. The Ho-F BDE is predicted to be comparable to the $\mathrm{Nd}-\mathrm{F} B D E$, but we did not observe $\mathrm{HoF}_{4}$ whereas $\mathrm{NdF}_{4}$ was observed. $\mathrm{PrF}_{4}$ and $\mathrm{TbF}_{4}$ have lower BDEs than for $\mathrm{CeF}_{4}$, consistent with the decomposition of the former two in the vapor. ${ }^{[21]}$ The tetrafluorides in the middle of the period ( $\mathrm{Sm}, \mathrm{Eu}$, and $\mathrm{Gd})$, those near the end of the period ( $\mathrm{Er}, \mathrm{Tm}, \mathrm{Yb}$, and $\mathrm{Lu}$ ), and $\mathrm{La}$ at the beginning of the period are likely not to be synthesized owing to the low Ln-F BDEs. This shows that the + III oxidation is clearly preferred for these Ln over the +IV. The population analysis shows that, except for $\mathrm{La}, \mathrm{Eu}, \mathrm{Gd}$, and $\mathrm{Lu}$, the tetrafluorides all prefer the + IV oxidation state. The ones noted still prefer the + III oxidation state for the tetrafluoride. The calculations further show that the observed $\mathrm{LnF}_{4}$ species are very stable against loss of $F_{2}$. The $\mathrm{Ln}$ in the + IV oxidation state have approximately $0.8 \mathrm{e}$ in the $5 \mathrm{~d}$ orbitals as a result of back-bonding from the $\mathrm{F}$ ligands, whereas those in the + III oxidation state have approximately 0.5 e in the $5 \mathrm{~d}$ orbitals. The early $\mathrm{Ln}$ up to $\mathrm{Sm}$ have some back-bonding into the $4 \mathrm{f}$ orbitals, but after $\mathrm{Sm}$, there is essentially no back-bonding into the $4 \mathrm{f}$ orbitals. The tetrafluorides in the + IV oxidation state, excluding $\mathrm{CeF}_{4}$, differ from the $\mathrm{OLnF}_{2}$ compounds, which are in the +III oxidation state or in a mixed + III/ + IV oxidation state ( $\mathrm{Pr}$ and $\mathrm{Tb}$ ). Addition of an electron to $\mathrm{LnF}_{4}$ or, equivalently, addition of $\mathrm{F}^{-}$to $\mathrm{LnF}_{3}$, leads to the $\mathrm{Ln}$ being in the $+\mathrm{III}$ oxidation state for all of the $\left[\mathrm{LnF}_{4}\right]^{-}$. The $\left[\mathrm{LnF}_{4}\right]^{-}$anions have about $0.45 \mathrm{e}$ in the $5 \mathrm{~d}$ orbitals as a result of back-bonding and there is essentially no back-bonding to the $4 \mathrm{f}$ orbitals. The calculated electron affinities verify that the $\mathrm{LnF}_{4}$ species are strong oxidizing agents and, in fact, would have some of the highest known electron affinities if they could be synthesized. Not surprisingly, the stable, observed $\mathrm{LnF}_{4}$ have the lower electron affinities. The calculated fluoride affinities show that the $\mathrm{LnF}_{3}$ are moderate to strong Lewis acids and that it should be possible to generate most of the $\left[\mathrm{LnF}_{4}\right]^{-}$anions as they are very stable to loss of an electron. In addition to the tetrafluorides, the trifluorides were also observed and further characterized and some difluorides were observed.

\section{Acknowledgments}

We gratefully acknowledge financial support from the Fond der Chemischen Industrie and the Dahlem Research School to T.V.-S. S.R. thanks the DFG graduate research training group, 1582/2 "Fluorine as a Key Element". D.A.D acknowledges the support of the US Department of Energy, Office of Basic Energy Sciences, Heavy Element Chemistry Program through a subcontract from Argonne National Laboratory. D.A.D. thanks the Robert Ramsay Fund at The University of Alabama. We thank Lester Andrews for providing some of the lanthanide metal targets.

Keywords: electronic structure - fluorine - high oxidation states $\cdot$ lanthanides $\cdot$ matrix-isolation

[1] T. Tsuchiya, T. Taketsugu, H. Nakano, K. Hirao, J. Mol. Struct. 1999, 461 462, 203-222.

[2] R. D. Wesley, C. W. DeKock, J. Chem. Phys. 1971, 55, 3866-3877.

[3] M. Lesiecki, J. W. Nibler, C. W. DeKock, J. Chem. Phys. 1972, 57, 1352 1353.

[4] M. Hargittai, Coord. Chem. Rev. 1988, 91, 35-88.

[5] L. Joubert, G. Picard, J.-J. Legendre, Inorg. Chem. 1998, 37, 1984-1991.

[6] G. Lanza, C. Minichino, ChemPhysChem 2009, 10, 507-511.

[7] S. Tsukamoto, H. Mori, H. Tatewaki, E. Miyoshi, Chem. Phys. Lett. 2009, $474,28-32$.

[8] A. Weigand, X. Cao, J. Yang, M. Dolg, Theor. Chem. Acc. 2010, 126, $117-$ 127.

[9] E. W. Kaiser, W. E. Falconer, W. Klemperer, J. Chem. Phys. 1972, 56, 5392 5398.

[10] R. H. Hauge, J. W. Hastie, J. L. Margrave, J. Less-Common Met. 1971, 23, 359-365.

[11] J. W. Hastie, R. H. Hauge, J. L. Margrave, J. Less-Common Met. 1975, 39, $309-334$.

[12] M. Chen, D. A. Dixon, X. Wang, H.-G. Cho, L. Andrews, J. Phys. Chem. A 2011, 115, 5609-5624.

[13] M. R. MacDonald, J. W. Ziller, W. J. Evans, M. R. MacDonald, J. W. Ziller, W. J. Evans, J. Am. Chem. Soc. 2011, 133, 15914-15917.

[14] M. R. MacDonald, J. E. Bates, M. E. Fieser, J. W. Ziller, F. Furche, W. J. Evans, J. Am. Chem. Soc. 2012, 134, 8420-8423.

[15] M. R. MacDonald, J. E. Bates, M. E. Fieser, J. W. Ziller, F. Furche, W. J. Evans, J. Am. Chem. Soc. 2013, 135, 9857-9868.

[16] G. Meyer, Angew. Chem. Int. Ed. 2014, 53, 3550-3551; Angew. Chem. 2014, 126, 3620-3622.

[17] J. W. Hastie, R. H. Hauge, J. L. Margrave, High Temp. Sci. 1971, 3, 56-72.

[18] N. N. Greenwood, A. Earnshaw, Chemistry of the Elements, Chapter 30, Pergamon Press, Oxford, 1994, pp. 1423-1449.

[19] Z. Mazej, J. Fluorine Chem. 2002, 118, 127-129.

[20] V. I. Spitsyn, Y. M. Kiselev, L. I. Martynenko, V. N. Prusakov, V. B. Sokolov, Dokl. Akad. Nauk SSSR 1974, 219, 621-624.

[21] E. W. Kaiser, W. A. Sunder, W. E. Falconer, J. Less-Common Met. 1972, 27, $383-387$

[22] L. R. Batsanova, Y. V. Zakhar'ev, A. A. Alovskii, Zh. Neorg. Khim. 1973, 18, 905-908.

[23] S. D. Gabelnick, G. T. Reedy, M. G. Chasanov, J. Chem. Phys. 1974, 60 $1167-1171$.

[24] T. Mikulas, M. Chen, D. A. Dixon, K. A. Peterson, Y. Gong, L. Andrews, Inorg. Chem. 2014, 53, 446-456.

[25] R. Hoppe, Rare Earths Mod. Sci. Technol. 1982, 3, 315-316.

[26] Z. Hu, G. Kaindl, B. G. Mueller, J. Alloys Compd. 1997, 246, 177-185.

[27] T. Vent-Schmidt, S. Riedel, Inorg. Chem. 2015, 54, 11114-11120.

[28] X. Wang, H.-G. Cho, L. Andrews, M. Chen, D. A. Dixon, H.-S. Hu, J. Li, J. Phys. Chem. A 2011, 115, 1913-1921.

[29] Y. Gong, X. Wang, L. Andrews, M. Chen, D. A. Dixon, Organometallics 2011, 30, 4443-4452.

[30] Y. Gong, L. Andrews, M. Chen, D. A. Dixon, J. Phys. Chem. A 2011, 115, $14581-14592$.

[31] R. G. Parr, W. Yang, Density-Functional Theory of Atoms and Molecules, Oxford University Press, New York, 1989.

[32] A. D. Becke, J. Chem. Phys. 1993, 98, 5648-5652.

[33] C. Lee, W. Yang, R. G. Parr, Phys. Rev. B 1988, 37, 785-789.

[34] N. Godbout, D. R. Salahub, J. Andzelm, E. Wimmer, Can. J. Chem. 1992, $70,560-571$.

[35] M. Dolg, H. Stoll, H. Preuss, J. Chem. Phys. 1989, 90, 1730.

[36] X. Cao, M. Dolg, J. Mol. Struct. 2002, 581, 139-147.

[37] C. Møller, M. S. Plesset, Phys. Rev. 1934, 46, 618-622. 
[38] J. A. Pople, J. S. Binkley, R. Seeger, Int. J. Quantum Chem. Symp. 2009 10, $1-19$.

[39] R. A. Kendall, T. H. Dunning Jr., R. J. Harrison, J. Chem. Phys. 1992, 96 6796-6806

[40] E. D. Glendening, C. R. Landis, F. Weinhold, J. Comput. Chem. 2013, 34 1429-1437; NBO 6.0: Natural Bond Orbital Analysis Program.

[41] E. D. Glendening, J. K. Badenhoop, A. E. Reed, J. E. Carpenter, J. A. Bohmann, C. M. Morales, C. R. Landis, F. Weinhold, http://nbo6.chem.wisc. edu/, Theoretical Chemistry Institute, University of Wisconsin, Madison Wl, 2013.

[42] F. Weinhold, in Encyclopedia of Computational Chemistry, Vol. 3 (Ed. P. v. R. Schleyer), John Wiley \& Sons, Chichester, 1998, pp. 1792-1811.

[43] F. Weinhold, C. R. Landis, Valency and Bonding: A Natural Bond Orbital Donor-Acceptor Perspective, University Press, Cambridge, 2005.

[44] A. E. Reed, L. A. Curtiss, F. Weinhold, Chem. Rev. 1988, 88, 899-926.

[45] Gaussian 09, Revision D.01, M. J. Frisch, G. W. Trucks, H. B. Schlegel, G. E. Scuseria, M. A. Robb, J. R. Cheeseman, G. Scalmani, V. Barone, B. Mennucci, G. A. Petersson, H. Nakatsuji, M. Caricato, X. Li, H. P. Hratchian, A. F. Izmaylov, J. Bloino, G. Zheng, J. L. Sonnenberg, M. Hada, M. Ehara, K. Toyota, R. Fukuda, J. Hasegawa, M. Ishida, T. Nakajima, Y. Honda, O. Kitao, H. Nakai, T. Vreven, J. A. Montgomery, Jr., J. E. Peralta, F. Ogliaro, M. Bearpark, J. J. Heyd, E. Brothers, K. N. Kudin, V. N. Staroverov, R. Kobayashi, J. Normand, K. Raghavachari, A. Rendell, J. C. Burant, S. S. Iyengar, J. Tomasi, M. Cossi, N. Rega, N. J. Millam, M. Klene, J. E. Knox, J. B.
Cross, V. Bakken, C. Adamo, J. Jaramillo, R. Gomperts, R. E. Stratmann O. Yazyev, A. J. Austin, R. Cammi, C. Pomelli, J. W. Ochterski, R. L. Martin, K. Morokuma, V. G. Zakrzewski, G. A. Voth, P. Salvador, J. J. Dannenberg S. Dapprich, A. D. Daniels, Ö. Farkas, J. B. Foresman, J. V. Ortiz, J. Cioslowski, D. J. Fox, Gaussian, Inc., Wallingford, CT, 2009.

[46] S. Riedel, T. Koechner, X. Wang, L. Andrews, Inorg. Chem. 2010, 49, $7156-7164$.

[47] T. Vent-Schmidt, F. Brosi, J. Metzger, T. Schloeder, X. Wang, L. Andrews, C. Mueller, H. Beckers, S. Riedel, Angew. Chem. Int. Ed. 2015, 54, 8279 8283; Angew. Chem. 2015, 127, 8397-8401.

[48] F. Brosi, T. Vent-Schmidt, S. Kieninger, T. Schlöder, H. T. Beckers, S. Riedel, Chem. Eur. J. 2015, 21, 16455-16462.

[49] V. N. Bukhmarina, A. Y. Gerasimov, Y. B. Predtechenskii, V. G. Shklyarik, Opt. Spektrosk. 1992, 72, 69-74.

[50] K. S. Thanthiriwatte, M. Vasiliu, S. R. Battey, Q. Lu, K. A. Peterson, L. Andrews, D. A. Dixon, J. Phys. Chem. A 2015, 119, 5790-5803.

[51] J. Saloni, S. Roszak, K. Hilpert, M. Miller, J. Leszczynski, Eur. J. Inorg. Chem. 2004, 1212-1218.

[52] L. Bencze, A. Feltrin, S. Nunziante-Cesaro, A. Popovic, Rapid Commun Mass Spectrom. 1996, 10, 1248-1258.

Received: October 17, 2015

Published online on January 20, 2016 